\title{
Application of FRET probes in the analysis of neuronal plasticity
}

\author{
Yoshibumi Ueda ${ }^{1+}$, Showming Kwok ${ }^{2}$ and Yasunori Hayashi ${ }^{1,3 *}$ \\ 'Brain Science Institute, RIKEN, Wako, Saitama, Japan \\ 2 Department of Brain and Cognitive Sciences, The Picower Institute for Learning and Memory, Massachusetts Institute of Technology, Cambridge, MA, USA \\ ${ }^{3}$ Brain Science Institute, Saitama University, Saitama, Japan
}

Edited by:

Masanobu Kano, The University of

Tokyo, Japan

Reviewed by:

Akihiro Yamanaka, Nagoya

University, Japan

Michiyuki Matsuda, Kyoto

University, Japan

${ }^{*}$ Correspondence:

Yasunori Hayashi, Brain Science

Institute, RIKEN, 2-1 Hirosawa,

Wako, Saitama, 351-0198, Japan

e-mail:yhayashi@brain.riken.jp;

yhayashi-tky@umin.ac.jp

${ }^{\dagger}$ Present address:

Yoshibumi Ueda, Department of

Hematology and Immunology,

Kanazawa Medical University,

Kahoku, Ishikawa, Japan
Breakthroughs in imaging techniques and optical probes in recent years have revolutionized the field of life sciences in ways that traditional methods could never match. The spatial and temporal regulation of molecular events can now be studied with great precision. There have been several key discoveries that have made this possible. Since green fluorescent protein (GFP) was cloned in 1992, it has become the dominant tracer of proteins in living cells. Then the evolution of color variants of GFP opened the door to the application of Förster resonance energy transfer (FRET), which is now widely recognized as a powerful tool to study complicated signal transduction events and interactions between molecules. Employment of fluorescent lifetime imaging microscopy (FLIM) allows the precise detection of FRET in small subcellular structures such as dendritic spines. In this review, we provide an overview of the basic and practical aspects of FRET imaging and discuss how different FRET probes have revealed insights into the molecular mechanisms of synaptic plasticity and enabled visualization of neuronal network activity both in vitro and in vivo.

Keywords: optical probes, synaptic plasticity, Förster resonance energy transfer, fluorescence lifetime imaging microscopy

\section{INTRODUCTION}

The brain is a highly interconnected functional network comprised of billions of neurons that communicate with each other at synapses. Throughout life, the neuronal connectivity that subserves brain function is modified and refined in an activitydependent manner, a phenomenon termed neuronal plasticity. Plasticity mechanisms can influence neuronal function and structure through modifications at the level of synapses, dendrites and axons (Citri and Malenka, 2008; Holtmaat and Svoboda, 2009).

Different forms of plasticity are tightly regulated by a complex network of signal transduction cascades, which are the results of protein-protein interaction, posttranslational modification, subcellular translocation of proteins, protein synthesis, etc. Therefore, the temporal and spatial precision of these events is critical to support proper brain function in the developing and mature brain. The development of probes that offer spatiotemporal detection of these cellular events is vital to our ability to examine these important molecular mechanisms in biological systems. For this purpose, optical microscopic imaging enables complex and varied neuronal signals to be captured with high temporal and spatial resolution from live biological samples.

Technological advances in the past two decades have made a significant contribution to our ability to extend fluorescent imaging techniques beyond that of simple morphological analysis. One of the key developments is Förster resonance energy transfer (FRET). First reported by Förster (1946), the technique describes how energy from a "donor" fluorophore can excite an "acceptor" fluorophore, resulting in light emission from the latter.
The efficiency of FRET depends on two main factors, the distance between the two fluorophores and their relative orientation. This feature enables the change in distance and angle between two fluorophores to be calculated, leading Lubert Stryer to call FRET a "molecular ruler" (Stryer, 1978). Using this property of FRET, various optical probes have been designed to detect aspects of different cellular functions in vitro and in vivo.

The sensitivity and compatibility of FRET imaging with live imaging are critical for analyzing the molecular mechanisms of neuronal circuit plasticity. In particular, much progress has been made in recent years regarding the analysis of synaptic plasticity of excitatory synapses in excitatory neurons, which are typically formed on dendritic spines (Hayashi and Majewska, 2005; Bosch and Hayashi, 2012). FRET imaging is now being applied in vivo and offers a unique opportunity to study how and when neurons or synapses change and which signaling events contribute to such changes in response to stimuli in the intact brain.

In this article, we will provide an overview of the basic and practical aspects of FRET imaging, summarize currently available FRET-based probes and then discuss how these probes advanced our understanding of the molecular mechanisms underlying neuronal plasticity, mainly hippocampal long-term potentiation (LTP).

\section{MONITORING in situ BIOCHEMICAL PROCESSES USING FRET-BASED PROBES}

In 1991, Tsien's group made the first attempt to image live cellular functions using FRET (Adams et al., 1991; Zhang et al., 2002). 
They attempted to visualize the intracellular dynamics of adenosine $3^{\prime}, 5^{\prime}$ - cyclic monophosphate (cAMP) by designing a probe based on cAMP-dependent protein kinase, in which the regulatory and catalytic subunits were labeled with fluorescein and rhodamine, respectively. Upon binding of cAMP, the regulatory subunit dissociates from the catalytic subunit, thereby eliminating FRET.

Subsequently, they also reported a voltage sensing FRET probe utilizing fluorescein-labeled lectin as a donor and oxonol, an anionic fluorescent compound, as an acceptor in living cells (Gonzalez and Tsien, 1995). At resting membrane potential, both dyes are localized on the outer leaflet of the plasma membrane and FRET occurs. Upon depolarization, negatively charged oxonol translocates to the inner leaflet of the plasma membrane and increases the distance from the donor, leading to a reduction in the efficiency of FRET.

However, FRET approaches using small molecular weight fluorescent compounds are technically demanding. For example, generation of the cAMP probe requires the cumbersome process of protein purification, in vitro chemical coupling with dyes and introduction into cells. The success of the oxonol-based probe largely owed to the identification of oxonol as a fluorescent molecule that travels across the plasma membrane upon a change in membrane voltage.

The emergence of genetically encoded FRET probes in the late 1990s dramatically changed the situation. This largely owes to the development and expansion of green fluorescent protein (GFP) and its color variants (Shaner et al., 2005). In a landmark study of genetically encoded FRET probes, Miyawaki et al. developed the first GFP-based calcium indicator, cameleon using cyan fluorescent protein (CFP) as a donor and yellow fluorescent protein (YFP) as an acceptor (Miyawaki et al., 1997). Cameleon consists of a calmodulin (CaM) protein fused with a M13 sequence (a 26-residue CaM binding peptide from myosin light-chain kinase), flanked by CFP and YFP. The gly-gly motif between CaM and the M13 peptide gives this probe its conformational flexibility. In the absence of calcium, CaM and the M13 sequence do not interact with each other. However, in the presence of calcium, they form a complex, which shortens the distance between the donor and acceptor fluorophores, allowing FRET to occur. Using this probe, they observed calcium dynamics in living cells and demonstrated the potential of FRET for the analysis of neuronal circuit dynamics. Since then, probes for other molecules such as cAMP, guanosine $3^{\prime}, 5^{\prime}$ - cyclic monophosphate (cGMP), and $\mathrm{Cl}^{-}$, small GTP-binding protein (small G-protein), phosphoinositide and signaling events e.g., phosphorylation have been developed (Table 1).

Compared to small molecular weight fluorescent moleculebased FRET probes, genetically encoded FRET probes offer a number of advantages. They can be constructed easily with standard molecular biological techniques, thus making probe design simple and flexible. They can be expressed in cells by simply introducing vector DNA into neurons without protein purification and chemical labeling. Use of an appropriate DNA transduction method or a promoter to express the probe allow cell-type specific labeling. Due to these technical advantages, the genetically-encoded FRET probes are now widely used standard tools in biological systems.

\section{STRATEGIES OF PROBE DESIGN}

Multiple genetically-encoded FRET probes have been developed for use in neuronal and non-neuronal cells. These probes can be classified into several categories depending on the approach used to detect different types of biological phenomena (Table 1, Figure 1).

\section{Cleavage-based approach}

The first reported GFP-based probe detecting Factor Xa activity employed the cleavage-based approach (Figure 1A) (Mitra et al., 1996). In this type of probe, a protease cleavage sequence was flanked by donor and acceptor fluorophores. Under basal conditions, FRET occurs between the fluorophores. However, cleavage of the target sequence causes a resultant separation of donor and acceptor molecules, leading to a decrease in FRET efficiency. The same approach was used to study other proteases including caspases (Xu et al., 1998; Onuki et al., 2002; Li et al., 2006; Joseph et al., 2011). One thing to note when using this type of probe is that the protease cleavage is irreversible. Therefore, it is not suitable for detecting a protease with high basal activity. Also, the measurement cannot be repeated multiple times as the uncleaved fraction decreases and the cleaved fraction accumulates over time.

\section{Intermolecular FRET approach}

The interaction between proteins can be monitored by intermolecular FRET, where one party of the protein complex is tagged by a donor and the other by an acceptor (Figure 1B). The interaction can be a heteromer of two different proteins or a homomer of the same protein. Application of this approach includes, small G-protein activity (Yasuda et al., 2006), 3-phosphoinositidedependent protein kinase 1 (PDK)-Akt (Calleja et al., 2007), phosphatase and tensin homolog deleted from chromosome 10 (PTEN)-myosin V (van Diepen et al., 2009), and protein-tyrosine phosphatase 1B (PTP1B)-receptor tyrosine kinases (RTKs) (Haj et al., 2002) interaction (Table 1). A variant of this approach is homomultimer FRET where a monomer in a polymeric protein complex is labeled with both donor and acceptor molecules (Figure 1C), which allows the polymerization status of the protein to be monitored. This was employed to detect actin polymerization/depolymerization (Okamoto et al., 2004).

The quantitative aspect of FRET is difficult to control in intermolecular FRET (when compared with intramolecular FRET) because the expression level of donor and acceptor molecules often varies amongst cells. In contrast, in an intramolecular FRET probe, the donor and acceptor are on the same molecule and thus, the ratio of the donor to acceptor is always constant. Also, endogenous proteins may participate in forming protein complexes and this can decrease intermolecular FRET efficiency. Therefore, with intermolecular FRET, the efficiency must be measured as an average of multiples cells or compared before and after a treatment (e.g., induction of synaptic plasticity) in the same cell. In practice, a donor which does not interact with an acceptor increases the background of the measurement, whereas excess levels of 
Table 1 | A list of genetically encoded FRET probes.

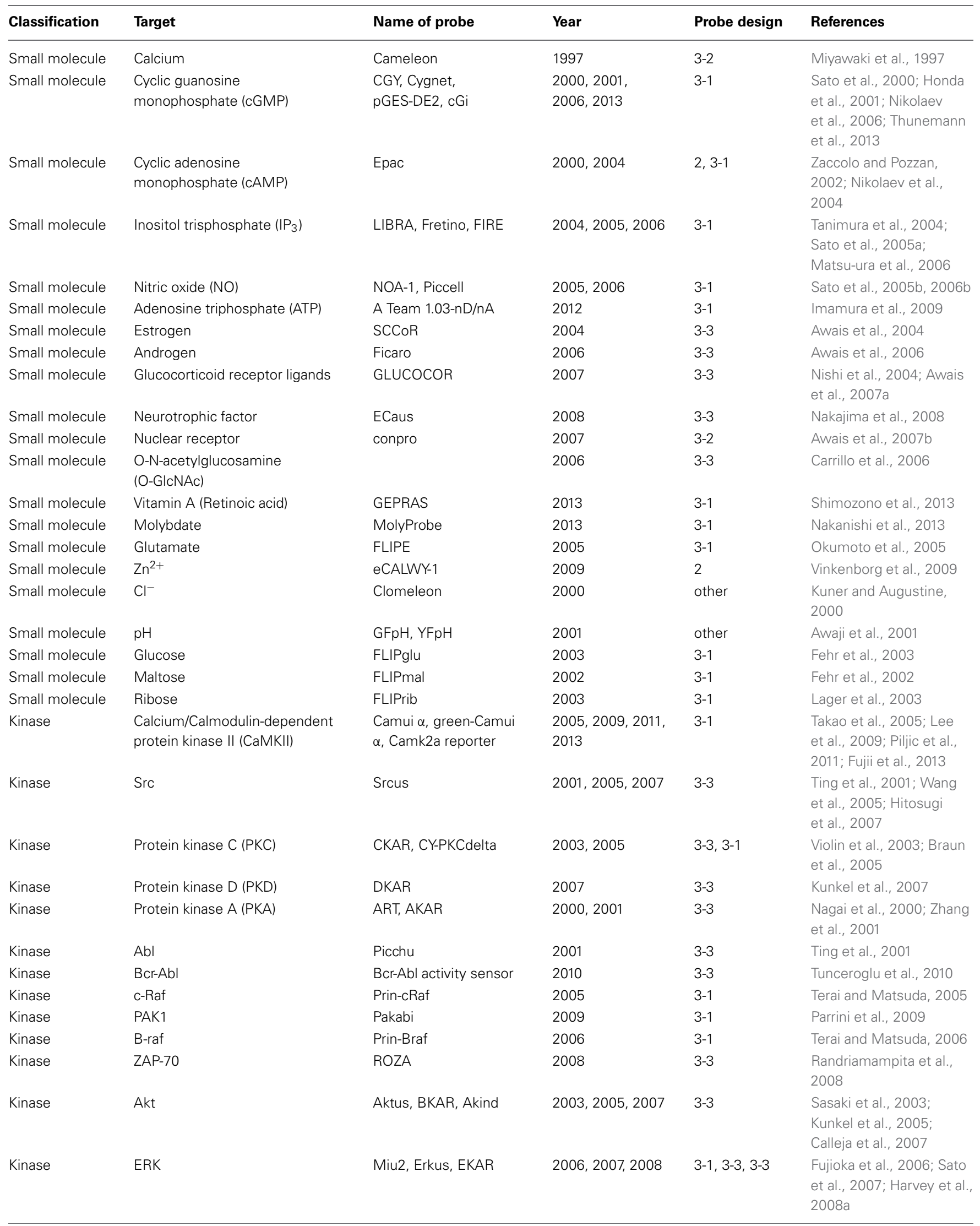


Table 1 | Continued

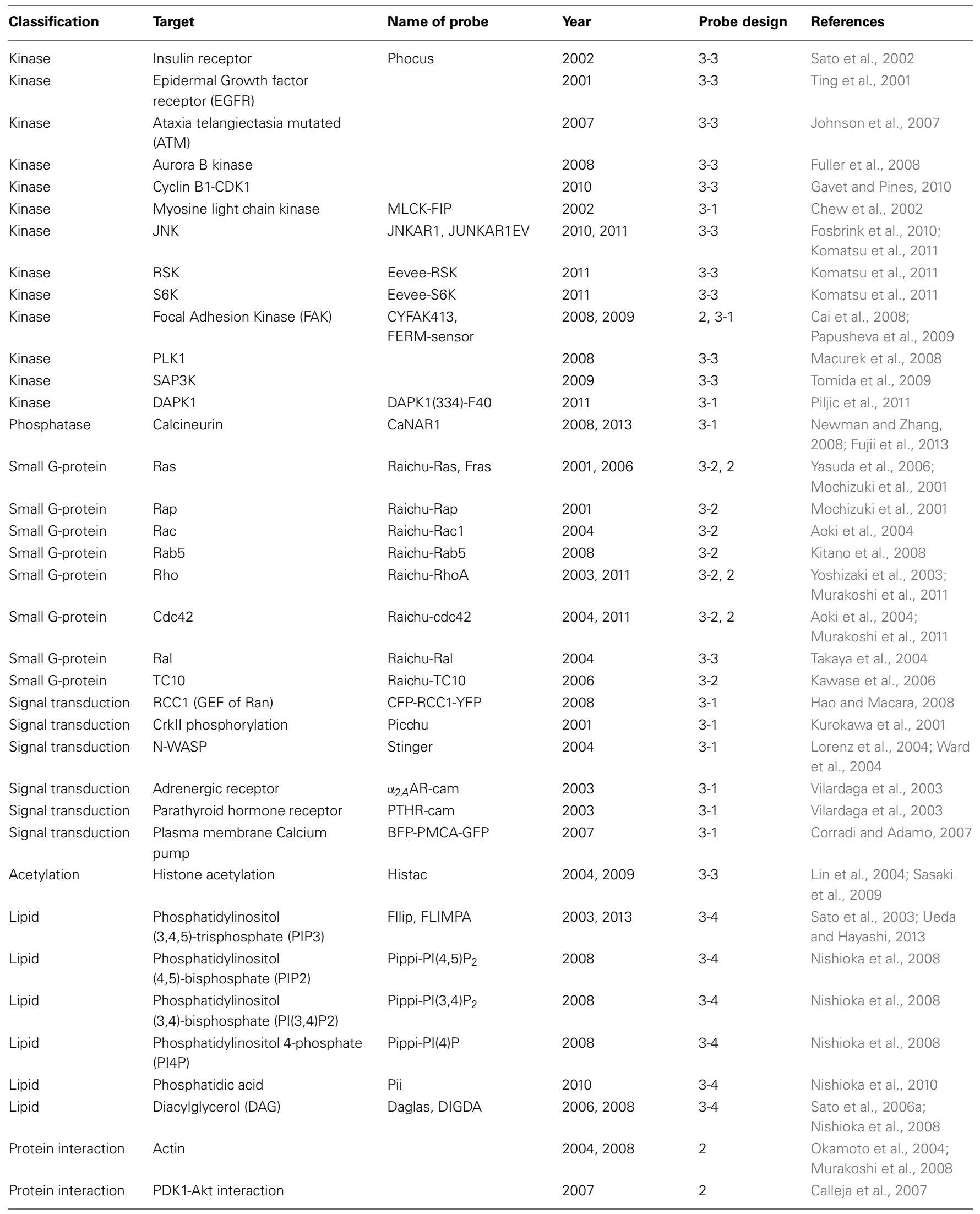


Table 1 | Continued

\begin{tabular}{|c|c|c|c|c|c|}
\hline Classification & Target & Name of probe & Year & Probe design & References \\
\hline Protein interaction & $\begin{array}{l}\text { Breast cancer resistance } \\
\text { protein/ATP-binding cassette } \\
\text { sub-family G member } \\
\text { (BCRP/ABCG) }\end{array}$ & & 2010 & 2 & Ni et al., 2010 \\
\hline Protein interaction & PTEN-Myosin V interaction & & 2009 & 2 & van Diepen et al., 2009 \\
\hline Protease & Caspase-3 & EGFP-DEVD-EBFP & 1998 & 1 & Xu et al., 1998 \\
\hline Protease & Caspase-8 & CFP-c3-YFP-c6-mRFP & 2002 & 1 & Onuki et al., 2002 \\
\hline Protease & Caspase-9 & SCAT9 & 2011 & 1 & Joseph et al., 2011 \\
\hline Protease & Caspase-7 & VDEVDc & 2006 & 1 & Li et al., 2006 \\
\hline Protease & Calpain activity & pYSCS & 2000 & 1 & Vanderklish et al., 2000 \\
\hline Protease & Presenilin & GFP-PSI-RFP & 2009 & 3-1 & Uemura et al., 2009 \\
\hline Other & Strain sensor & stFRET & 2008 & 3-1 & Meng et al., 2008 \\
\hline Other & Membrane potential & $\begin{array}{l}\text { VSFP, Mermaid, } \\
\text { ArcLight, } \\
\text { VSFP-Butterfly }\end{array}$ & $\begin{array}{l}2001,2008,2012, \\
2013\end{array}$ & $3-1$ & $\begin{array}{l}\text { Sakai et al., 2001; Tsutsui } \\
\text { et al., 2008; Jin et al., } \\
\text { 2012; Akemann et al., } \\
2013\end{array}$ \\
\hline Other & Myosin II & GSIdCB & 1998,2006 & 3-1 & $\begin{array}{l}\text { Suzuki et al., 1998; Zeng } \\
\text { et al., } 2006\end{array}$ \\
\hline Other & HIV Rev protein & YRGnC-11ad & 2005 & 3-1 & Endoh et al., 2005 \\
\hline
\end{tabular}

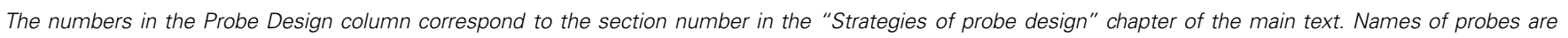
shown. See the webpage by Dr. Michiyuki Matsuda http://www.lif.kyoto-u.ac.jp/labs/fret/e-phogemon/unifret.htm for updated information.

acceptor molecules usually does not cause a problem (Okamoto and Hayashi, 2006). Therefore, whenever possible, excess acceptor molecules should be used.

\section{Intramolecular FRET approach}

This approach detects the conformational change of the probe via a change in the distance and angle of donor and acceptor proteins located on the same molecule. Because both fluorophores are on the same molecule, complications such as the differential redistribution of the donor and acceptor proteins and heterogeneity in the expression level of donor and acceptor among cells can be eliminated. Using this approach, many different probes have been generated to enable the detection of covalent modifications of proteins, membrane voltage, small biological molecules, and signal transduction (Table 1). One can design a probe to detect conformational change that is intrinsic to the protein of interest or design a fusion protein that changes its conformation upon the occurrence of a specified biological event. Advantage of intramolecular FRET is relative ease of constructing probe which shows FRET. But it is sometimes difficult to find right position of the fluorophore so that external stimuli change the FRET efficiency.
Intrinsic conformation change of protein. If a protein of interest changes its conformation by activation/inactivation, one can design a probe to detect the conformational change as a way of monitoring the activity level (Figure 1D). This may be accomplished by flanking the protein with a donor and an acceptor or inserting one or both of the fluorophore(s) between the domains. This approach has been successfully employed for $\mathrm{Ca}^{2+} / \mathrm{CaM}$ dependent protein kinase II (CaMKII) (Takao et al., 2005; Kwok et al., 2008; Fujii et al., 2013), calcineurin (Fujii et al., 2013), c-raf (Terai and Matsuda, 2005), p21 protein-activated kinase 1 (PAK1) (Parrini et al., 2009), B-raf (Terai and Matsuda, 2006), regulator of chromosome condensation 1 (RCC1) (Hao and Macara, 2008), vitamin A receptor (Shimozono et al., 2013) and to monitor changes in membrane potential (Tsutsui et al., 2008; Akemann et al., 2012). X-ray crystal structure is a useful guide to identify locations on a protein where the donor and acceptor pair can be placed.

Conformation change induced by a specific protein interaction. Activation or inactivation of a protein can trigger an interaction with a specific target protein. By using such an interaction, one can design a FRET probe to detect the activation of a protein 


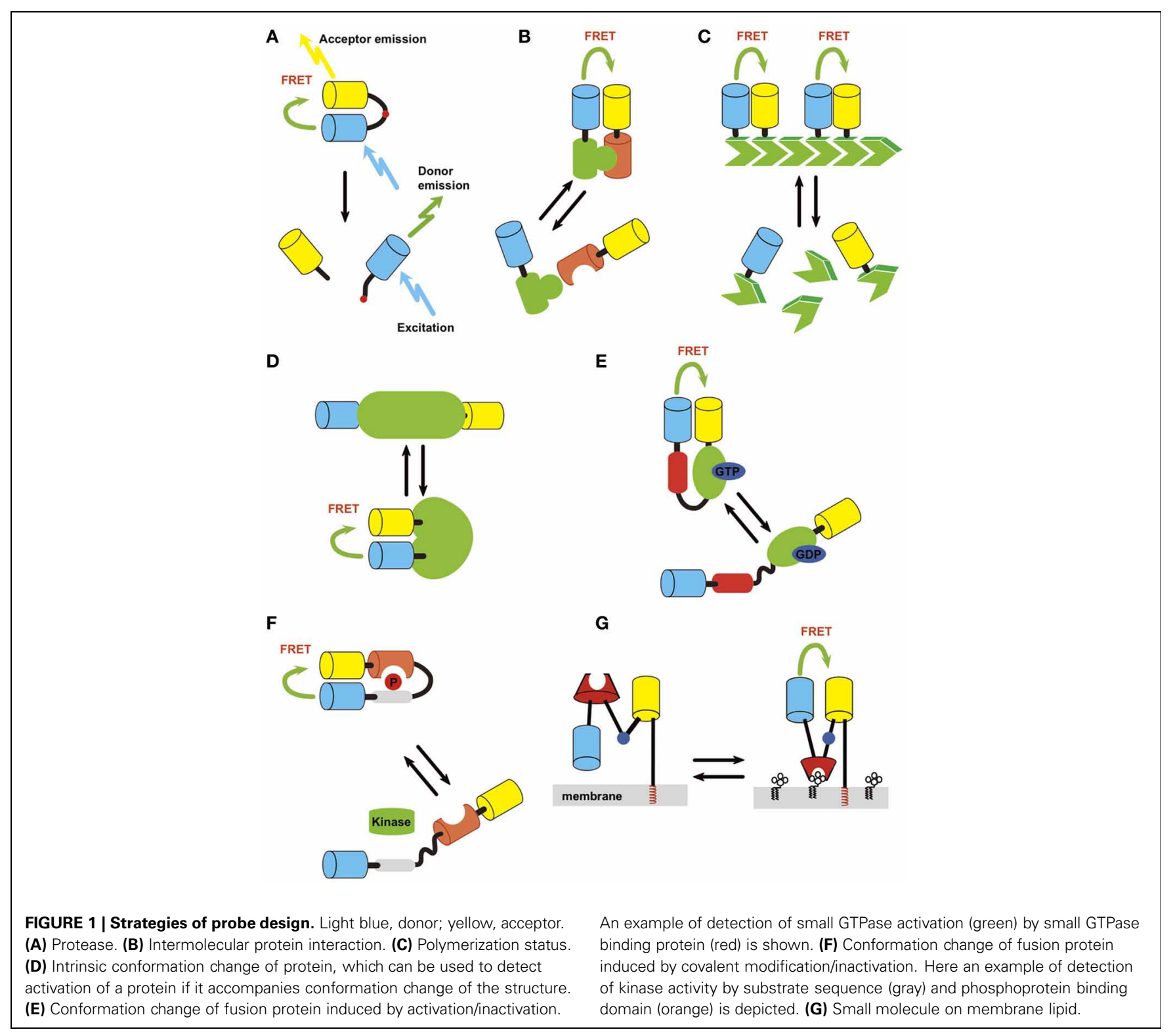

(Figure 1E). The cameleon probe mentioned above falls into this category. Another example is the Raichu series of probes that were developed to observe the activity of small G-proteins (Mochizuki et al., 2001). The basic structure of Raichu probes is comprised of four modules; a donor, an acceptor, a G-protein, and a Gprotein-binding domain from its binding partner (Figure 1E). The inactive GDP-bound form does not interact with each other the G-protein-binding domain. Upon binding with GTP, the Gprotein and G-protein-binding domain interact with each other to bring the two fluorophores into close proximity, thereby leading to FRET. This probe design strategy has been applied to Ras, Rho family protein, and other small G-proteins (Hao and Macara, 2008; Kiyokawa et al., 2011).

Conformation change induced by a covalent modification of protein. This type of probe consists of a donor and an acceptor, which flank a substrate domain that can be covalently modified by the protein of interest and a protein domain that specifically recognizes the covalently modified protein (Figure 1F). When the protein is covalently modified, it binds to the adjacent recognition domain, leading to a conformational change in the entire molecule, resulting in a change in FRET. By making use of specific kinase substrate and phosphor-protein recognition domains, this strategy has been applied to the design of FRET sensors for kinases and phosphatases including PKA (Zhang et al., 2001), C (Violin et al., 2003), and D (Kunkel et al., 2007), Akt (Sasaki et al., 2003), and Src (Ting et al., 2001). It should be noted that this type of probe actually detects a temporal integration of both kinase and phosphatase activity. Also, there may be kinases or phosphatases other than the target protein, which also phosphorylate or dephosphorylate the probe. 
Small molecules on membranes. Using a similar strategy, small molecules on membranes can also be measured (Figure 1G). In this case, one of the fluorophores is tethered to the membrane through rigid $\alpha$-helical linkers whereas the other fluorophore retains its flexibility via a gly-gly hinge. A specific lipid-binding domain is inserted in-between. When a small molecule binding domain interacts with its target of interest, a conformational change occurs through the hinge, resulting in an increase in FRET efficiency. This strategy has mainly been used to design probes for lipid second messengers such as phosphatidylinositol 3,4-bisphosphate $\left(\mathrm{PI}(3,4) \mathrm{P}_{2}\right)$, phosphatidylinositol 4,5-bisphosphate $\left(\mathrm{PI}(4,5) \mathrm{P}_{2}\right)$, phosphatidylinositol 3,4,5-trisphosphate $\left(\mathrm{PIP}_{3}\right)$, phosphatidylinositol 4-monophosphate (PI(4)P), and diacylglycerol (DAG) (Sato et al., 2003, 2006a; Nishioka et al., 2008; Ueda and Hayashi, 2013).

\section{DETECTION OF FRET}

Several imaging methods for FRET detection are used in typical biological laboratory settings (Miyawaki, 2003; Yasuda, 2006, 2012).

\section{Ratiometric FRET detection}

In ratiometric FRET detection, the acceptor and donor images are acquired separately and the ratio of fluorescent intensity between the two images is subsequently calculated. When FRET occurs, the acceptor/donor ratio increases. Because any fluorescent microscopy (e. g., wide field, confocal, two-photon) can be used for this measurement, ratiometric FRET measurement is often used, though it is not best for several reasons. When performing this type of imaging, maximum care must be taken to minimize spectral bleed-through, to properly subtract background and to take into account the fluorophore relocalization. These factors make imaging in small structures particularly challenging. For example, CFP, a donor fluorophore that is often paired with YFP as an acceptor, can bleed into the YFP channel, thereby decreasing the signal/noise ratio. Hence to minimize bleed-through, a suitable band-pass filter should be used, even if the overall brightness of the signal is compromised. Also, background subtraction has to be performed with great care, as a subtle change in background can have a significant effect on the signal ratio. The issue of probe relocalization should also be carefully considered. This may be particularly problematic when measuring intermolecular FRET between two different molecules, which may differentially relocalize during neuronal plasticity. For example, if donor moves while the acceptor does not, it will cause an apparent change in fluorescent ratio without an actual change in protein interaction. This situation can be circumvented by using a probe with intramolecular FRET, where both donor and acceptor are on the same molecule or intermolecular FRET between homomers, where both are expected to move in parallel (Ni and Zhang, 2010). It is also possible to mathematically correct the FRET by separately measuring the amount of local acceptor. But in such cases, it is better to employ fluorescent life-time imaging microscopy, which relies only on donor fluorescence (see below).

\section{Acceptor bleaching}

When the acceptor is photobleached with an appropriate wavelength, the donor fluorescence is dequenched and increased. This maneuver, called acceptor bleaching, gives a quantitative reading of FRET as it depends only on the donor fluorescence intensity. Excitation light wavelength, intensity, and duration must be carefully chosen to photobleach only the acceptor fluorophore. The photobleaching of the donor fluorophore will underestimate the FRET. This can be done by simply illuminating the donor protein without an acceptor and making sure that donor fluorescence does not photobleach. It should be noted that the photobleaching of an acceptor is irreversible and therefore, acceptor photobleaching is a terminal experiment where only a single, specific and accurate static measure of FRET efficiency is needed (Miyawaki, 2003). Obviously, for this reason, acceptor bleaching is not compatible with time-lapse imaging.

\section{Fluorescent lifetime imaging}

The third approach to quantifying FRET relies on a parameter of fluorescence, called fluorescence lifetime (Yasuda, 2006). When a fluorescent molecule is excited, it emits fluorescence in a decaying manner from the time of activation, typically in exponential fashion. When FRET occurs, the donor fluoresecence lifetime is shortened. Because fluorescence lifetime is unaffected under a wide range of concentrations and does not depend on acceptor fluorescence, it is less prone to artifact caused by a change in the local concentration of donor and acceptor, which is especially important in heterooligomer FRET. In contrast, ratiometric measurement can show a pseudopositive signal caused by bleedthrough between fluorescence channels, which can be an issue when measuring FRET from a structure where protein composition can change. Therefore, fluorescence lifetime imaging microscopy (FLIM) is the ideal choice for FRET detection.

There are largely two different methods of FLIM, time and frequency domain measurements (Yasuda, 2006). The time domain measures the fluorescence decay after a brief (< picoseconds) excitation pulse, while frequency domain measures lifetime by modulating the excitation light intensity and the detector gain differently (heterodyning) at high frequency (Yasuda, 2006). Both imaging systems are costly because FLIM requires a dedicated light-source and time-resolved detection. However, if one already has a two-photon microscope, adding components onto the existing system is straightforward. Current systems allow the detection of FRET signals at second order time resolution from single dendritic spines (Murakoshi et al., 2011), which is still slower than the ratiometric imaging that can go to video rate.

For the time domain measurement, time correlated single photon counting is currently widely used. This method measures the time elapses between an excitation pulse and an emitted single photon, which is binned into a histogram. The data will then be fitted to exponential curve (Yasuda, 2006). When two states are expected, such as in the case where both bound and unbound FRET pair coexist, it is possible to do double exponential fitting to obtain the ratio of two components (Yasuda, 2006). However, whether fitting double exponential is appropriate or not to a given FRET pair should be carefully considered based on the protein structure. For example, if donor forms a homodimer, it is enough 
to complicate the situation. When endogenous counterpart exists, often the case in a cell, the dimer can be either between two exogenous donor molecules or between one donor and one endogenous counterpart, in addition to the dimer made of two endogenous molecules. As a result, the acceptor interacts with either two, one or zero fluorescent molecules. Mathematically, it is possible to perform triple (or more) exponential fitting. However, such measurement requires (1) bright sample, (2) capability of hardware that captures high photon counts over a large number of pixels rapidly, and (3) ease of sophisticated data analysis. Cellular autofluorescence also complicates the analysis (Colyer et al., 2012). To circumvent this, one can calculate average lifetime of the photons, which theoretically gives lifetime in single exponential. This will not give absolute proportion of component showing FRET but by comparing the average lifetime over time, will give sufficient information even from a noisy decay curve not suitable for fitting (Lee et al., 2009; Murakoshi et al., 2011).

Another issue of the time domain measurement is the "dead zone" of the sampling. For example, in a system set up on a Tisapphire laser based two-photon microscope, the repetition rate of the laser is at $80 \mathrm{MHz}$ or every $12.5 \mathrm{~ns}$. There is always a dead zone of sampling between each cycle, where the acquisition system must reset for the next cycle. Given that many fluorescent proteins have lifetime of 2-5 ns range, the dead zone can limit the effective range of fitting and underestimate especially the component with longer lifetime. Recent studies that introduced widefield photon-counting detector and phasor analysis might provide a new approach to perform FLIM experiments, alleviating these shortfalls (Kwok et al., 2008; Colyer et al., 2012).

\section{CHOICE OF FLUORESCENCE PROTEINS}

To effectively measure the change in the distance and angle between two fluorophores in a FRET construct, it is critical to start with a suitable pair of fluorescent molecules with efficient FRET. The efficiency of FRET $(E)$ depends on several parameters characteristic to each pair of fluorescent proteins. Förster distance $\left(R_{0}\right)$, the distance at which the energy transfer efficiency is $50 \%$, depends on the overlap of donor emission and acceptor excitation $(J)$, quantum yield of the donor $\left(Q_{0}\right)$, and acceptor molar extinction coefficient $\left(\varepsilon_{A}\right)$. As the values for $J, Q_{0}$, and $\varepsilon_{A}$ increase, so does the value of $R_{0}$, which in turn produces a larger $E$ value. So far, CFP (or an improved version such as Cerulean or K26R/N164H mutant of ECFP) and YFP (such as Venus) is the most commonly for ratiometric FRET measurements. A CFPYFP pair gives a $R_{0}$ of $4.8-5.2 \mathrm{~nm}$, depending on the variants used (Rizzo et al., 2006; Kwok et al., 2008; Lam et al., 2012). Recently, it was reported that the Clover and mRuby 2 offers Förster radius of $6.3 \mathrm{~nm}$ and is currently considered to be the best FRET pair available to date (Lam et al., 2012).

For FLIM, enhanced GFP (EGFP) is often used as a donor, and paired with either monomeric red fluorescent protein (mRFP) or mCherry as an acceptor. The acceptor brightness is not an issue in FLIM as it relies solely on the donor fluorescence measurement. Therefore, non-fluorescent, quencher proteins such as REACh (Ganesan et al., 2006), darkVenus (Kwok et al., 2008), and super REACh (Lee et al., 2009) may also be used as acceptors to donor EGFP. Ideally, the donor should show a single lifetime with FLIM, which is the case for EGFP. The original enhanced CFP (ECFP) is not optimal as it shows two lifetime components, in addition to its relatively weak fluorescence. Cerulean and mTurquoise 2 are both brighter and have mono exponential decay, therefore, can be used when the cyan range is needed (Rizzo et al., 2004; Goedhart et al., 2012).

EGFP has a weak tendency to dimerize (Zacharias et al., 2002), which can lead to issues with protein aggregation, depending on the protein it is fused with (Lantsman and Tombes, 2005). Therefore, monomerized versions of EGFP, such as the A206K mutant (the amino acid numbering is based on wild type GFP) is preferred for FRET experiments as it will reduce any pseudopositive FRET signal caused by non-specific aggregation. However, in certain cases, such as in cleavage-based protease sensors, the dimerization of donor and acceptor molecules can be beneficial to increase the difference in FRET efficiency before and after cleavage. In fact, a random mutagenesis study to enhance FRET efficiency of caspase probe lead to the identification of a CyPet-YPet pair (Nguyen and Daugherty, 2005), which was subsequently shown to form a dimer between donor and acceptor (Ohashi et al., 2007). For comprehensive review on fluorescence proteins, please refer to Shaner et al. (2005) and Newman et al. (2011).

\section{APPLICATION OF FRET PROBES TO STUDY NEURONAL CIRCUIT DYNAMICS}

Numbers of FRET probes have been developed and tested in various cell types. Here we list some of the recent research accomplishments using FRET probes in neuronal circuits. See Table 1 for an extended list of various FRET probes.

\section{$\mathrm{Ca}^{2+}$}

Intracellular $\mathrm{Ca}^{2+}$ plays an important role in regulating various cellular functions such as signaling, gene regulation, cell death, and survival. Under basal conditions, the intracellular $\mathrm{Ca}^{2+}$ concentration is maintained at low levels by various $\mathrm{Ca}^{2+}$. extrusion and sequestration mechanisms. Upon neuronal activation, local intracellular $\mathrm{Ca}^{2+}$ concentration increases through influx from the extracellular fluid or efflux from the intracellular pool (Hayashi and Majewska, 2005). Different sources of $\mathrm{Ca}^{2+}$ can have distinct kinetics, subcellular localization and functions. Therefore, it is not very surprising that a $\mathrm{Ca}^{2+}$-sensing FRET probe was one of the first genetically encoded FRET sensors ever made (Miyawaki et al., 1997). A popular use of this type of probe is to detect neuronal circuit activity through a detection of action potentials as $\mathrm{Ca}^{2+}$ influx into cells via voltage dependent $\mathrm{Ca}^{2+}$ channels. The activity of hundreds of neurons can be simultaneously monitored (Wallace et al., 2008).

Since Miyawaki et al. characterized cameleon, the first $\mathrm{Ca}^{2+}$ sensing FRET probe, various probes with different affinities to $\mathrm{Ca}^{2+}$ have been reported (Miyawaki, 2005). Cameleon was expanded into the yellow cameleon series, which had greater sensitivity to $\mathrm{Ca}^{2+}$ and better signal/noise ratio (Nagai et al., 2004; Horikawa et al., 2010). Griesbeck et al. utilized troponin $\mathrm{C}$ and I to generate the Tn series $\mathrm{Ca}^{2+}$ sensor protein (Heim and Griesbeck, 2004). Cameleon has been mainly applied to zebrafish (Mizuno et al., 2013) and C. elegans (Haspel et al., 2010). Recently 
YC-Nano 140, new version of cameleon, was expressed to barrel cortex of mice using adeno-associated virus vector and showed different responses between two groups of neurons which are projected to different regions in neocortex (Chen et al., 2013).

Using a separate approach not involving FRET for its principle mode of detection, Nakai et al. generated G-CaMP (Nakai et al., 2001). G-CaMP was engineered to express CaM and a M13 peptide inserted in the $\beta$-barrel wall of GFP, which ultimately distorts its overall structure of GFP and quenches its fluorescence. An increase in $\mathrm{Ca}^{2+}$ concentration induces CaM and M13 peptide to interact, which then leads to a conformation change in the $\beta$-barrel. This in turn changes the protonation status of the fluorophore and dequenches the fluorescence. A related $\mathrm{Ca}^{2+}$ sensor termed pericam also utilizes a similar strategy (Nagai et al., 2001). Recently, B-GECO and R-GECO, a blue and red version of G-CaMP were developed to allow the simultaneous detection of calcium in more than one subcellular compartments or cell types (Zhao et al., 2011). With improvements in the sensitivity of probes and detection methods, it is now possible to visualize the $\mathrm{Ca}^{2+}$-influx in single dendritic spines evoked by unitary excitatory postsynaptic potential (epsp) (Ohkura et al., 2012). Currently G-CaMP is becoming the first choice for $\mathrm{Ca}^{2+}$ imaging, especially in vivo because it is convenient to detect the $\mathrm{Ca}^{2+}$ responses with one channel. However, a recent report comparing the sensitivity between G-CaMP3 and YCs in Purkinje cells of acute cerebellar slice from mice (Yamada et al., 2011) showed that YC exhibited better response than G-CaMP3, indicating that optimal probes need to be carefully chosen in a given brain region of interest.

\section{A CaMKII activity sensor, Camui}

CaMKII is a member of the serine/threonine protein kinase family that is highly expressed in the brain, especially at the postsynaptic density (PSD) of excitatory synapses (Kennedy et al., 1983; Chen et al., 2005). CaMKII has been highly implicated in both induction and maintenance of functional and structural LTP (Lisman et al., 2002; Matsuzaki et al., 2004). The activation of CaMKII precedes the structural enlargement of stimulated spines, suggesting that CaMKII is a molecular trigger of downstream processes that lead to structural changes. In addition, the CaMKII has structural role at the synapse through its capacity to bundle F-actin (Okamoto et al., 2007, 2009).

Under basal conditions, CaMKII is kept inactive by intrasubunit steric block of the substrate-binding site ( $\mathrm{S}$ site) in the kinase domain by a pseudosubstrate region within the autoinhibitory domain (Lisman et al., 2002). Binding of $\mathrm{Ca}^{2+} / \mathrm{CaM}$ to the regulatory domain (adjacent to the autoinhibitory domain) alters its conformation and disrupts the inhibitory interaction at the $S$ site. This disruption releases the kinase domain from autoinhibition and allows it to rapidly self-phosphorylate threonine 286 (T286) of CaMKII, as well as other substrates. CaMKII autophosphorylation at T286 prevents the autoinhibitory domain from binding with the $\mathrm{T}$ site of the catalytic domain and from blocking the kinase activity, thereby allowing the kinase to retain substantial activity even in the absence of $\mathrm{Ca}^{2+}$. Thus, this holoenzyme remains active for a prolonged period of time, significantly outlasting that of $\mathrm{a} \mathrm{Ca}^{2+}$ spike. Based on these observations, CaMKII was proposed as a memory molecule, which can be used to store long term information after a synapse undergoes LTP (Lisman et al., 2002).

However, direct demonstration of the persistent activation of CaMKII after the induction of LTP was lacking because of a deficiency in effective methods to detect the spatial and temporal activation of CaMKII at the single spine level. To circumvent this, a FRET probe, Camui, was engineered by employing the intramolecular FRET approach to detect the conformational change associated with CaMKII activation by fusing donor and acceptor fluorophores to both termini of CaMKII (Takao et al., 2005; Kwok et al., 2008). Camui shows FRET in its basal inactive state. Addition of ATP, CaM, and $\mathrm{Ca}^{2+}$ leads to a rapid and persistent decrease in FRET. The conformational change due to binding of $\mathrm{Ca}^{2+} / \mathrm{CaM}$ and autophosphorylation is accountable for the change in FRET. This persistent, $\mathrm{Ca}^{2+}$-independent change in FRET is absent when ATP is omitted or when a kinase dead mutant is used. Furthermore, a phosphoblocking mutant (T286A) stops the persistent change in FRET, whereas a phosphomimicking mutant (T286D) shows decreased FRET without $\mathrm{Ca}^{2+}$ stimulation. Hence, Camui detects the collective activation of CaMKII by the binding of $\mathrm{Ca}^{2+} / \mathrm{CaM}$ and the autophosphorylation at T286. Using a FLIM version of Camui, green-Camui $\alpha$, Lee et al. discovered that CaMKII activity is only transient $(<2 \mathrm{~min})$ after the induction of structural LTP (sLTP) even though CaMKII activation is required for sustaining structural synaptic plasticity. This is much shorter than what had been believed (Lee et al., 2009).

We investigated the spatial and temporal regulation of CaMKII in rapid ocular dominance (OD) plasticity in layer II/III of ferret visual cortex in vivo, a paradigmatic model for studying the role of sensory experience in shaping cortical neural circuits (Mower et al., 2011). By taking advantage of the superficial location of layer II/III pyramidal neurons for optical detection of Camui signals (Figure 2A), we found that brief monocular deprivation ( $\mathrm{MD}, 4 \mathrm{~h}$ ) leads to activation of CaMKII at most synapses in the deprived eye domains (Figure 2B). However, a change in CaMKII activity was not observed in the spines located in binocular and non-deprived eye domains following the same visual manipulation. Four hours of MD also lead to the elimination of a small fraction of spines in the deprived eye domain, whose basal CaMKII activity was lower than the average CaMKII activity in the same cortical site. The spines that persisted after MD had either high basal CaMKII activity or increased activity. Therefore, the emerging picture of the role of CaMKII activity in vivo is that (1) the eliminated spines have low CaMKII activity (although not all spines with low activity are removed) and (2) high CaMKII activity might have a protective role for spines and these preserved spines could potentially serve as a substrate for the reorganization of intracortical presynaptic partners.

At first, this result is seemingly at odds with the study by Lee et al., where they observed a transient activation of CaMKII by LTP induction with glutamate uncaging. However, this result most likely reflects the ability of CaMKII to respond to different neuronal activity patterns (De Koninck and Schulman, 1998; Fujii et al., 2013). In the study by Lee et al. (2009), 


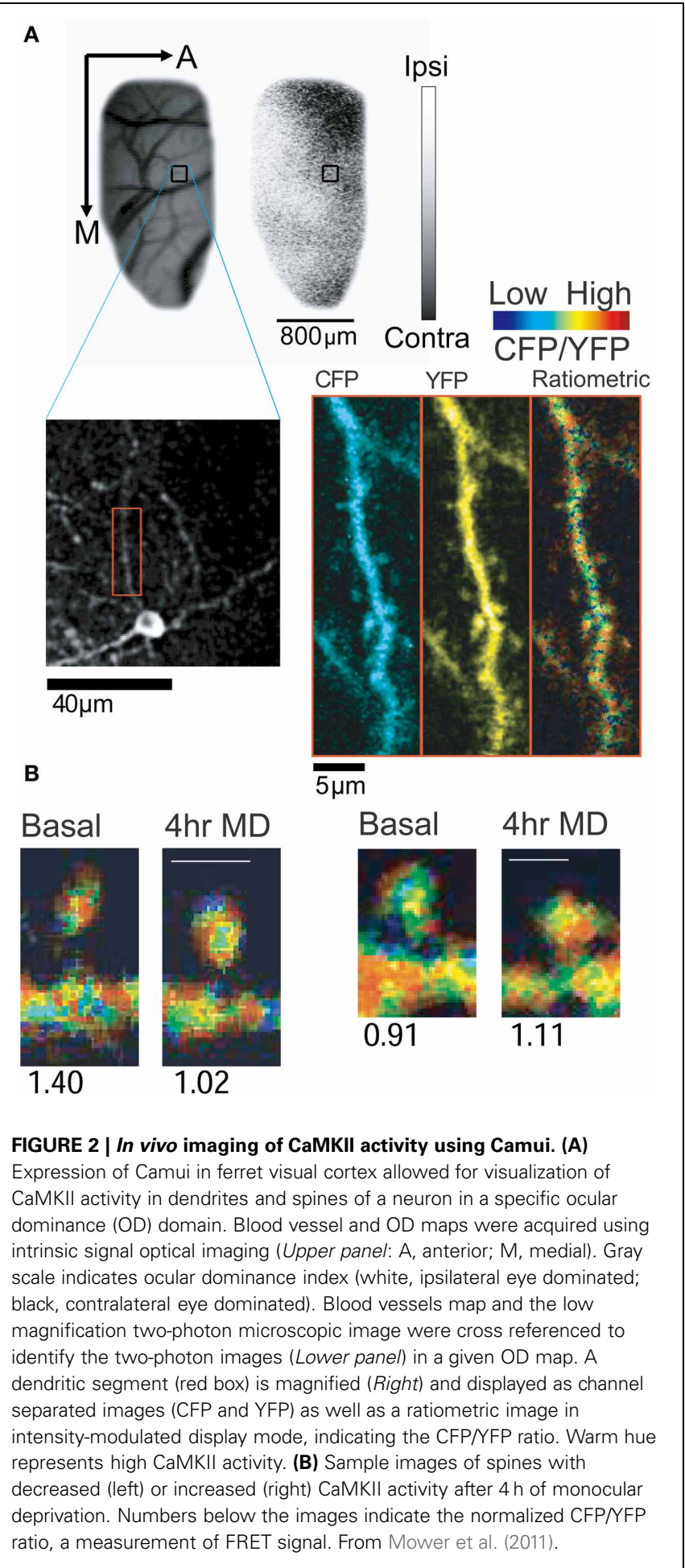

CaMKII is activated by local $N$-methyl-D-aspartate type glutamate receptor (NMDA-R) activation. However, in the visual cortex, it likely detects an integration of complex local and global activity patterns that encompass both Hebbian and homeostatic mechanisms. Further studies are required to fully elucidate the role of CaMKII in synaptic plasticity both in vitro and in vivo.

\section{Small G-protein}

Small G-protein family, including Ras, Rho, Ran, Rab, Sar/Arf subfamilies, is a large group of signaling molecules that control various cellular functions (Saneyoshi and Hayashi, 2012). The activity of small G-protein is controlled by intrinsic GTPase activity and by the type of guanine nucleotide it is bound with. GTP-bound form consists active form, which is converted into GDP-bound form by the GTPase activity. The cycle between GDP-bound inactive and GTP-bound active forms is regulated by three classes of proteins, guanine nucleotide exchange factors (GEFs), GTPase-activating proteins (GAPs), and guanine nucleotide dissociation inhibitors (GDIs) (Saneyoshi and Hayashi, 2012). GEFs exchange GDP bound on a small G-protein with GTP, which leads to an activation of signaling activity of the small G-protein. The GTP-bound forms of G-protein lapse into inactive forms when GAP induces activation of GTPase activity that converts the bound GTP to GDP. GDI removes GDP-bound inactive forms of G-proteins from cell membranes and therefore maintains them in inactive forms.

Two family member of Ras family, Ras itself and Rap are implicated in synaptic plasticity. Zhu et al. showed that Ras relays the NMDA-R and CaMKII signaling that drives synaptic delivery of $\alpha$-amino-3-hydroxy-5-methyl-4-isoxazolepropionic acid type glutamate receptors (AMPA-Rs) during LTP (Zhu et al., 2002). In contrast, Rap mediates NMDA-R-dependent removal of synaptic AMPA-Rs that occurs during LTD. Thus, Ras and Rap serve as independent regulators for potentiating and depressing central synapses. Ras is also implicated in spine formation. The expression of a constitutively active Ras in neocortex neurons lead to an increase in spine density (Gartner et al., 2005). Conversely, a loss of SynGAP, a Ras-GAP that expresses specifically in the brain, leads to an increase in spine formation and enlargement of spine size (Vazquez et al., 2004).

In order to elucidate the Ras activity during LTP in the spines of hippocampal neurons, Yasuda et al. designed an intermolecular FLIM-based probe to detect Ras activity, in which momomeric EGFP was tagged to the N-terminus of Ras, and two momomeric RFPs were attached to the $\mathrm{N}$ - and C-termini of the Ras binding domain (RBD) of Raf (Yasuda et al., 2006). When Ras at the plasma membrane is activated, $\mathrm{RBD}$ is recruited to the membrane and binds to Ras, resulting in an increase in FRET. Using this probe, they investigated the activity of G-proteins in single dendritic spines in CA1 pyramidal neurons during sLTP. After the induction of sLTP, Ras was activated, which was then maintained for $30 \mathrm{~min}$ (Yasuda et al., 2006). Interestingly, the Ras signaling is not restricted to spines but spreads over $10 \mu \mathrm{m}$ into dendritic shafts and eventually reaches neighboring spines, which can subsequently undergo sLTP with only weak stimulation (a stimulation that would normally induce only temporary potentiation) (Harvey et al., 2008b). These data suggest that the spread of Ras-dependent signaling is necessary for the local regulation of the LTP induction threshold.

Rho family G-proteins, including ras homolog family member (Rho), ras-related C3 botulinum toxin substrate (Rac), and cell division control protein 42 homolog (Cdc42), are small GTP binding proteins that control the actin cytoskeleton (Komatsu et al., 2011; Saneyoshi and Hayashi, 2012). Because actin is the 
major cytoskeletal protein in dendritic spines, the role of the Rho family G-proteins on the maintenance and rearrangement of spine morphology has been investigated (Saneyoshi and Hayashi, 2012). The expression of a constitutively active form of Racl in hippocampal pyramidal neurons leads to an increase in the number (Tashiro et al., 2000), length and width of spines (Zhang and Macara, 2006), while a dominant negative had the opposite effect (Nakayama et al., 2000; Zhang and Macara, 2006; Impey et al., 2010). In contrast, a constitutively active form of RhoA reduces the density of spines (Tashiro et al., 2000; Impey et al., 2010) and causes a simplification of dendritic branch pattern (Nakayama et al., 2000). Inhibition of RhoA activity leads to an increase in the number of spines in some neurons (Tashiro et al., 2000; Impey et al., 2010). Cdc42 is also implicated in spine morphogenesis (Tashiro et al., 2000; Irie and Yamaguchi, 2002).

Murakoshi also applied the same Ras probe design strategy to construct probes for Rho family protein (Murakoshi et al., 2011). The temporal and spatial extent of activity spreading over the dendritic shaft was investigated (Murakoshi et al., 2011). Activity of both RhoA and Cdc42 was maintained for up to $30 \mathrm{~min}$, which is consistent with the observation that the filamentous (F-) actin/globular (G-) actin equilibrium moves toward F-actin after LTP induction (Okamoto et al., 2004, see below). RhoA spreads with a length constant of $4.5 \mu \mathrm{m}$ along the dendrite. On the other hand, Cdc42 activity was restricted only in the stimulated spine, whose length constant is $1.9 \mu \mathrm{m}$.

\section{Phosphatidylinositol 3,4,5-Trisphosphate $\left(P P_{3}\right)$}

$\mathrm{PIP}_{3}$ is a phosphoinositide that plays an important role in a variety of cellular functions. $\mathrm{PIP}_{3}$ is produced from phosphatidylinositol 4,5-bisphosphate $\left(\mathrm{PIP}_{2}\right)$ by phosphoinositide 3-kinase (PI3K) in response to hormone and neurotransmitter while PTEN converts $\mathrm{PIP}_{3}$ back to $\mathrm{PIP}_{2}$. In hippocampal pyramidal neurons, $\mathrm{PIP}_{3}$ is crucial for maintaining AMPA-R clustering during LTP (Arendt et al., 2010). $\mathrm{PIP}_{3}$ also regulates neuronal polarity, dendritic arborization, and nerve growth factor-induced axonal filopodia formation (Jaworski et al., 2005; Ketschek and Gallo, 2010). In order to exert these functions, local $\mathrm{PIP}_{3}$ accumulation leads to the recruitment of effector proteins such as Akt (Thomas et al., 2001), WASP family Verprolin-homologous protein (WAVE) (Oikawa et al., 2004) and GEF of small G proteins to specific subcellular compartments (Han et al., 1998; Shinohara et al., 2002; Innocenti et al., 2003).

In order to investigate $\mathrm{PIP}_{3}$ function and regulation in spines, we developed a FLIM-based $\mathrm{PIP}_{3}$ FRET probe, FLIMPA3, by concatenating a donor, a specific $\mathrm{PIP}_{3}$-binding domain, flexible di-glycine hinge, and an acceptor tethered to the membranes through rigid $\alpha$-helical linkers (Sato et al., 2003; Murakoshi et al., 2008; Ueda and Hayashi, 2013) (Figure 1G). When FLIMPA3 was expressed in hippocampal CA1 pyramidal neurons, we found that $\mathrm{PIP}_{3}$ showed greater accumulation in spines than in dendritic shafts under basal conditions (Ueda and Hayashi, 2013). $\mathrm{PI} 3 \mathrm{~K}$ inhibitor treatment decreased $\mathrm{PIP}_{3}$ accumulation in spines, indicating that $\mathrm{PIP}_{3}$ accumulation is largely due to basal PI3K activity in spines. This result is consistent with a previous report in which PI3K is ubiquitously localized in neuronal cells, but only becomes active after AMPA-R binding (Man et al., 2003). During
sLTP, $\mathrm{PIP}_{3}$ in spines was reduced. Application of a PTEN inhibitor did not significantly change the reduction in $\mathrm{PIP}_{3}$. Additionally, the reduction of $\mathrm{PIP}_{3}$ after sLTP was highly correlated with $\mathrm{PIP}_{3}$ enrichment before sLTP induction. Therefore, the reduction in $\mathrm{PIP}_{3}$ during sLTP is likely to be due to the addition of membrane from the dendritic shaft. Interestingly, whilst $\mathrm{PIP}_{3}$ globally decreases in spines during sLTP, we observed a specific accumulation of $\mathrm{PIP}_{3}$ in spinules, filopodia-like protrusions found on spines. When $\mathrm{PIP}_{3}$ in spinules was blocked by a PI3K inhibitor that reduces $\mathrm{PIP}_{3}$ levels, the number of spinules after sLTP were diminished, indicating that $\mathrm{PIP}_{3}$ in spinules regulates spinule formation.

Electron microscopic studies found that spinules could be trans-synaptically endocytosed by presynaptic terminals as separate vesicles from the postsynaptic side (Spacek and Harris, 2004). Therefore, the trans-endocytosis of spinules may serve as a mechanism for retrograde signaling or may aid postsynaptic membrane remodeling by removing excess membrane (Spacek and Harris, 2004). Accumulated $\mathrm{PIP}_{3}$ in spinules that traffic to the presynaptic side may act as a retrograde signal or contribute to the formation of new synapses with functional presynaptic boutons.

\section{Extracellular Signal-regulated Kinase (ERK)}

ERK is a serine/threonine protein kinase that belongs to the mitogen-activated protein kinase (MAPK) family, which plays important roles in a variety of cellular functions such as cell differentiation, proliferation, and survival (Chang and Karin, 2001). In neuronal circuits, ERK is involved in a wide range of functions including the regulation of dendritic protein synthesis (Impey et al., 1998a,b; Roberson et al., 1999; Davis et al., 2000; Patterson et al., 2001; Waltereit et al., 2001), morphological changes in dendritic spines (Wu et al., 2001; Goldin and Segal, 2003) and hippocampal LTP and memory formation in vivo (Giovannini et al., 2001). Abnormal ERK signaling is associated with mental retardation (Costa et al., 2002).

In order to obtain information about the spatiotemporal dynamics of ERK activity in neuronal cells, several FRET-based probes have been developed. Miu2 detects the conformational change of ERK activation by flanking ERK with CFP and YFP (Fujioka et al., 2006). Erkus is based on the detection of substrate protein phosphorylation (Sato et al., 2007) (Figure 1F). The ERK substrate sequence was obtained from EGFR and fused to the phospho-binding domain from FHA2 by a flexible peptide linker. The D domain, a sequence that selectively binds to ERK was attached to increase the specificity and efficiency of phosphorylation. This fusion protein was flanked by CFP and YFP. When phospho-substrate peptide is phosphorylated by active ERK, the phosphoprotein-binding domain interacts with the phospho-substrate peptide, leading to a change in overall conformation, which can be detected by a change in FRET efficiency. EKAR uses a similar approach but with a different substrate and a phosphoprotein-binding domain (Harvey et al., 2008a).

Using EKAR in hippocampal pyramidal neurons, Harvey et al. observed ERK activity induced by back-propagating action potentials (Harvey et al., 2008a). Stimulated bursts of action potentials caused global $\mathrm{Ca}^{2+}$ influx through voltage-gated $\mathrm{Ca}^{2+}$ channels, leading to Ras activation, an upstream molecule of 
ERK (Yasuda et al., 2006; Harvey et al., 2008b). After stimulation, ERK activity reached a peak by around $5 \mathrm{~min}$, then gradually decreased, and finally returned to basal levels by $30 \mathrm{~min}$. The time course of ERK activation was longer than that of Ras, consistent with the idea that ERK is the downstream effector of Ras. They also investigated ERK activity in the somatic cytoplasm and nucleus of neuronal cells. After theta-burst stimulation, ERK activity in both regions was up-regulated in a parallel manner, indicating that global $\mathrm{Ca}^{2+}$ influx through VGCCs can diffuse rapidly between these two compartments (Harvey et al., 2008a).

\section{Chloride sensor}

$\mathrm{Cl}^{-}$ion regulates neuronal properties such as intracellular $\mathrm{pH}$, cell volume, and fluid secretion (Duran et al., 2010). More importantly, $\mathrm{Cl}^{-}$is a major carrier of electrical current in inhibitory synaptic transmission mediated by GABA and glycine receptors. The basal level of intracellular chloride ions $\left(\mathrm{Cl}^{-}\right)$ is maintained by a number of mechanisms including chloride transporter system that consist of $\mathrm{Na}^{+}-\mathrm{Cl}^{-}, \mathrm{Na}^{+}-\mathrm{K}^{+}-2 \mathrm{Cl}^{-}$, and $\mathrm{K}^{+}-\mathrm{Cl}^{-}$transporters, and the activation of tonic GABA receptors, calcium-activated $\mathrm{Cl}^{-}$channels, cAMP-activated $\mathrm{Cl}^{-}$channels, cell-volume regulated anion channels, and transporters localized within subcellular organelles (Duran et al., 2010). Since all these factors sum up to determine the intracellular $\mathrm{Cl}^{-}$concentration, it is of a great interest to visualize the dynamics of intracellular $\mathrm{Cl}^{-}$.

The chloride sensor, Clomeleon, consists of CFP, a flexible peptide linker, and a $\mathrm{Cl}^{-}$sensitive YFP (with S65G, S72A, K79R, T203Y, H231L mutations) (Kuner and Augustine, 2000). YFP intensity is quenched in the presence of $\mathrm{Cl}^{-}$, thereby changing FRET efficiency in a $\mathrm{Cl}^{-}$concentration-dependent manner. Using this probe, in hippocampal dissociated cultures of neurons and glial cells, the developmental time course of $\mathrm{Cl}^{-}$concentration was investigated (Kuner and Augustine, 2000). While the $\mathrm{Cl}^{-}$concentration in glia cells was low throughout embryonic and postnatal stages, the concentration in neurons was higher at embryonic stages, and then decreased during postnatal development, consistent with the observation that activation of GABA receptors in immature neurons leads to neuronal excitation rather than inhibition (Kuner and Augustine, 2000). Using this probe, it was also possible to observe $\mathrm{Cl}^{-}$influx through GABA receptors in hippocampal CA1 pyramidal neurons following interneuron stimulation (Berglund et al., 2006). However, at this point, the sensitivity of the $\mathrm{Cl}^{-}$sensor is not as good as to visualize $\mathrm{Cl}^{-}$ influx induced by unitary inhibitory postsynaptic current (ipsc). This would require further elaboration of the probe.

\section{Actin}

Actin is the major cytoskeletal protein in dendritic spines (Matus, 2005; Okamoto et al., 2009). It exists in equilibrium between two forms, globular (G-actin) and filamentous actin (F-actin) (Okamoto et al., 2009; Saneyoshi and Hayashi, 2012). Actin has a rapid turnover time within the dendritic spine. An experiment using fluorescence recovery after photobleaching (FRAP) of GFPfused actin revealed that over $85 \%$ of actin in dendritic spines is dynamically turning over, with an average time constant of $44 \mathrm{~s}$ (Star et al., 2002). This dynamic turnover is the underlying molecular basis of motility and morphological changes of spines (Okamoto et al., 2004, 2009; Matus, 2005; Honkura et al., 2008).

As in non-neuronal cells, F-actin in dendritic spines undergoes a unique directional treadmilling as revealed with experiments using a photoactivatable (PA)-GFP-actin or a photoconvertable fluorescent protein (Honkura et al., 2008; Frost et al., 2010). G-actin is added to the barbed end of F-actin at the periphery of dendritic spines and at the base of the dendritic spine, F-actin is continuously disassembled to G-actin at the pointed end of actin. Taken together, there is an overall directional movement of F-actin from the periphery toward the spine base (Honkura et al., 2008; Frost et al., 2010). Another way to look at this is to divide the actin population into different pools. The first pool of F-actin, found at the periphery, has a relatively high turnover of about 40 s (Honkura et al., 2008). The second pool is the population that resides at the base of spines, with a turnover time of $17 \mathrm{~min}$ (Honkura et al., 2008). These two pools are relatively static and help to maintain the overall spine shape and size. In addition, there is a third pool that appears after LTP induction (Honkura et al., 2008). The turnover time of this pool is $2-15 \mathrm{~min}$ and it spreads all over the spine. This pool is required to maintain dendritic spine enlargement upon sLTP induction. If this pool extrudes into the dendritic shafts then sLTP was not maintained.

Actin exists in equilibrium between F-actin/G-actin but it was not known how the F-actin/ G-actin equilibrium changes during synaptic plasticity. This is because the dendritic spine is too small and does not show discrete F-actin structure that is observable with light microscopy. To circumvent this, an intermolecular FRET approach was used to monitor the F-actin/ G-actin equilibrium (Okamoto et al., 2004). The distance between actin monomers in F-actin is $55 \AA$, which is within the appropriate range to be detected with FRET. Actin was tagged with CFP and YFP as a donor and an acceptor, respectively. Using this approach, Okamoto et al. observed actin dynamics in hippocampal CA1 pyramidal neuronal cells during bidirectional plasticity (Okamoto et al., 2004). Upon tetanic stimulation, the equilibrium of F-actin/G-actin shifted toward F-actin, which was accompanied by spine enlargement (Figure 3). In contrast, prolonged low-frequency stimulation, typically inducing LTD, lead to spine shrinkage and actin depolymerization. This evidence suggests that the equilibrium of F-actin/ G-actin regulates bidirectional structural plasticity.

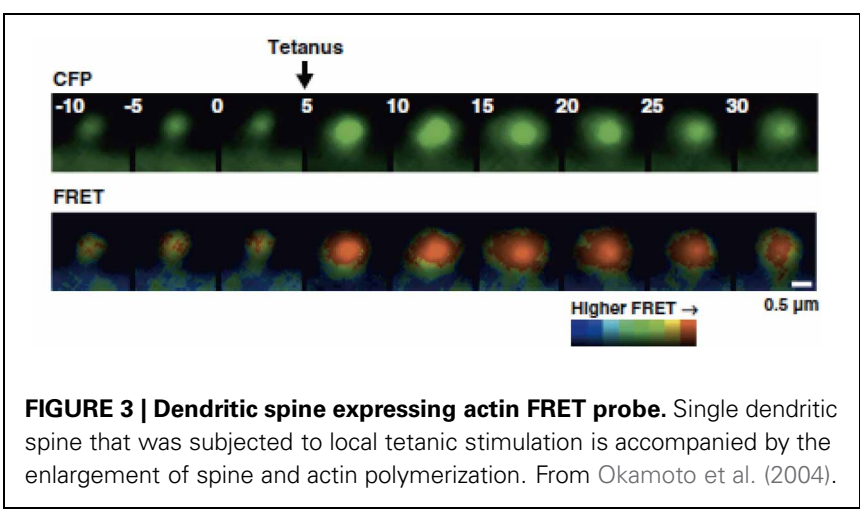




\section{Voltage sensors}

Electrophysiological recordings are considered to be the "gold standard" technique for measuring neuronal membrane potentials. However, several drawbacks to this method exist, such as the invasive nature of the technique and limitations in the number of neurons that can be measured simultaneously. To circumvent these issues, small molecular weight voltage-sensitive fluorescent dyes have been used with some success. The main disadvantage of using small molecular weight voltage-sensitive fluorescent dyes is the lack of cell-type specificity, because the dyes are generally bogus loaded and taken up by cells in a non-specific manner. It is also important to note that the dyes can diminish over time or cause toxicity. Therefore, these dyes are mostly suited for use in acute experiments.

Genetically-encoded membrane potential sensors, VSFP2 (Sakai et al., 2001) and Mermaid (Tsutsui et al., 2008), allow us to visualize the membrane voltage of a large number of individual neurons with high temporal resolution. Both probes are based on a membrane embedded phosphatase that senses voltage, Ci-VSP, a protein derived from tunicate, Ciona intestinalis. Ci-VSP is composed of a voltage-sensor domain (VSD) and phosphatase domain (Murata et al., 2005). The phosphatase domain on the C-terminus was replaced with a fluorophore pair fused in tandem. Membrane depolarization causes a conformational change in the overall structure, leading to a decrease in the distance between fluorophores, and ultimately a change in FRET efficiency. In cultured cortical neurons expressing Mermaid, a stimulated burst $(30$ pulses at $100 \mathrm{~Hz})$ of spikes could be observed (Tsutsui et al., 2008). Recently, VSFPbutterfly and ArcLight were developed, where the acceptor was moved from the C-terminus to the N-terminus (Akemann et al., 2012, 2013; Jin et al., 2012). VSFP-butterfly has been used to visualize changes in membrane voltage elicited by the stimulation of a single whisker in layer $2 / 3$ pyramidal neurons in the mouse barrel cortex (Akemann et al., 2012). The authors also succeeded in visualizing spontaneous slow brain oscillations traveling over the somatosensory cortex (Akemann et al., 2012).

\section{CONCLUDING REMARKS}

In 1990s, the readout of synaptic plasticity was mostly limited to the size of electrical response of synapse. The data were analyzed by applying to mathematical model of synaptic transmission established from studies on neuromuscular junction, which later turned out to be not compatible to the central synapse and caused a huge confusion in the field. The title of a review written by Sanes and Lichtman "Can molecules

\section{REFERENCES}

Adams, S. R., Harootunian, A. T., Buechler, Y. J., Taylor, S. S., and Tsien, R. Y. (1991). Fluorescence ratio imaging of cyclic AMP in single cells. Nature 349, 694-697. doi: 10.1038/349694a0

Akemann, W., Mutoh, H., Perron, A., Park, Y. K., Iwamoto, Y., and Knöpfel, T. (2012). Imaging neural

explain long-term potentiation?" (Sanes and Lichtman, 1999), well represents the sentiment around that time on the neverending debate on the mechanism of LTP. Fortunately, the recent introduction of technologies to optically measure the activity of molecules involved in synaptic plasticity has drastically changed the field and successfully clarified a number of points that remained unsolved before and provided new concepts of synaptic plasticity.

In the quest to understand the molecular mechanisms underpinning neuronal circuit plasticity, FRET has played a critical role in revealing important insights into the spatiotemporal dynamics of the key players. However, limiting its further application, it has been empirically known that it is difficult to establish transgenic mice expressing FRET probes (Hara et al., 2004). This may be due to the repeat of very similar DNA sequence (CFP and YFP) within transgene (Kamioka et al., 2012). It is also possible that probe proteins work as a gain-of-function mutant that hampers the function of endogenous proteins (Hara et al., 2004). Nonetheless, number of transgenic animals expressing FRET probes has been increasing (Hara et al., 2004; Berglund et al., 2006; Zhang et al., 2010; Yamaguchi et al., 2011; Kamioka et al., 2012; Wang et al., 2012; Thunemann et al., 2013). Additional difficulty lies in the detection of FRET, especially in the in vivo preparation. In practice, the animal's heartbeat and breathing introduce not only the movement of the cells during imaging but also the hemodynamic noise and therefore changes the absorbance in the optical path of the excitation and emission of fluorescence (Akemann et al., 2012). This will affect the accuracy of FRET data acquisition. With continued technological advances, it will be possible to apply FRET to increasingly complex preparations, even in vivo, to fully understand the complicated neuronal signaling processes that occur in the ever-changing brain.

\section{AUTHOR CONTRIBUTIONS}

Yoshibumi Ueda, Showming Kwok, and Yasunori Hayashi jointly wrote the manuscript.

\section{ACKNOWLEDGMENTS}

We thank Takeo Saneyoshi, Akihiro Goto, Ryan A. Colyer, and Lily $\mathrm{Yu}$ for comments on the manuscript. This work was supported by RIKEN, NIH grant R01DA17310, Grant-inAid for Scientific Research (A) and Grant-in-Aid for Scientific Research on Innovative Area "Foundation of Synapse and Neurocircuit Pathology" from the Ministry of Education, Culture, Sports, Science and Technology of Japan (Yasunori Hayashi).

Aoki, K., Nakamura, T., and Matsuda, M. (2004). Spatio-temporal regulation of Racl and Cdc42 activity during nerve growth factor-induced neurite outgrowth in PC12 cells. J. Biol. Chem. 279, 713-719. doi: 10.1074/jbc.M306382200

Arendt, K. L., Royo, M., FernandezMonreal, M., Knafo, S., Petrok, C. N., Martens, J. R., et al. (2010).
PIP3 controls synaptic function by maintaining AMPA receptor clustering at the postsynaptic membrane. Nat. Neurosci. 13, 36-44. doi: 10.1038/nn.2462

Awais, M., Sato, M., Lee, X., and Umezawa, Y. (2006). A fluorescent indicator to visualize activities of the androgen receptor ligands in single living cells. Angew. Chem. 
Int. Ed. Engl. 45, 2707-2712. doi: 10.1002/anie. 200503185

Awais, M., Sato, M., Sasaki, K., and Umezawa, Y. (2004). A genetically encoded fluorescent indicator capable of discriminating estrogen agonists from antagonists in living cells. Anal. Chem. 76, 2181-2186. doi: 10.1021/ac030410g

Awais, M., Sato, M., and Umezawa, Y. (2007a). Optical probes to identify the glucocorticoid receptor ligands in living cells. Steroids 72, 949-954. doi: 10.1016/j.steroids. 2007.08.006

Awais, M., Sato, M., and Umezawa, Y. (2007b). Imaging of selective nuclear receptor modulatorinduced conformational changes in the nuclear receptor to allow interaction with coactivator and corepressor proteins in living cells. Chembiochem 8, 737-743. doi: 10.1002/cbic. 200700001

Awaji, T., Hirasawa, A., Shirakawa, H., Tsujimoto, G., and Miyazaki, S. (2001). Novel green fluorescent protein-based ratiometric indicators for monitoring $\mathrm{pH}$ in defined intracellular microdomains. Biochem. Biophys. Res. Commun. 289, 457-462. doi: 10.1006/bbrc. 2001.6004

Berglund, K., Schleich, W., Krieger, P., Loo, L. S., Wang, D., Cant, N. B., et al. (2006). Imaging synaptic inhibition in transgenic mice expressing the chloride indicator, Clomeleon. Brain Cell Biol. 35, 207-228. doi: 10.1007/s11068-008-9019-6

Bosch, M., and Hayashi, Y. (2012). Structural plasticity of dendritic spines. Curr. Opin. Neurobiol. 22, 383-388. doi: 10.1016/j.conb.2011. 09.002

Braun, D. C., Garfield, S. H., and Blumberg, P. M. (2005). Analysis by fluorescence resonance energy transfer of the interaction between ligands and protein kinase Cdelta in the intact cell. J. Biol. Chem. 280, 8164-8171. doi: 10.1074/jbc. M413896200

Cai, X., Lietha, D., Ceccarelli, D. F., Karginov, A. V., Rajfur, Z., Jacobson, K., et al. (2008). Spatial and temporal regulation of focal adhesion kinase activity in living cells. Mol. Cell. Biol. 28, 201-214. doi: 10.1128/MCB.01324-07

Calleja, V., Alcor, D., Laguerre, M., Park, J., Vojnovic, B., Hemmings, B. A., et al. (2007). Intramolecular and intermolecular interactions of protein kinase B define its activation in vivo. PLoS Biol. 5:e95. doi: 10.1371/journal.pbio.0050095

Carrillo, L. D., Krishnamoorthy, L., and Mahal, L. K. (2006). A cellular FRET-based sensor for beta-O-GlcNAc, a dynamic carbohydrate modification involved in signaling. J. Am. Chem. Soc. 128, 14768-14769. doi: 10.1021/ ja065835+

Chang, L., and Karin, M. (2001). Mammalian MAP kinase signalling cascades. Nature 410, 37-40. doi: $10.1038 / 35065000$

Chen, J. L., Carta, S., SoldadoMagraner, J., Schneider, B. L., and Helmchen, F. (2013). Behaviour-dependent recruitment of long-range projection neurons in somatosensory cortex. Nature 499, 336-340. doi: 10.1038/nature12236

Chen, X., Vinade, L., Leapman, R. D., Petersen, J. D., Nakagawa, T., Phillips, T. M., et al. (2005). Mass of the postsynaptic density and enumeration of three key molecules. Proc. Natl. Acad. Sci. U.S.A. 102, 11551-11556. doi: 10.1073/pnas.0505359102

Chew, T. L., Wolf, W. A., Gallagher, P. J., Matsumura, F., and Chisholm, R. L. (2002). A fluorescent resonant energy transfer-based biosensor reveals transient and regional myosin light chain kinase activation in lamella and cleavage furrows. J. Cell Biol. 156 543-553. doi: 10.1083/jcb.200110161

Citri, A., and Malenka, R. C. (2008). Synaptic plasticity: multiple forms, functions, and mechanisms. Neuropsychopharmacology 33, 18-41. doi: 10.1038/sj.npp.1301559

Colyer, R. A., Siegmund, O. H., Tremsin, A. S., Vallerga, J. V., Weiss, S., and Michalet, X. (2012). Phasor imaging with a widefield photon-counting detector. J. Biomed. Opt. 17, 016008. doi: 10.1117/1.JBO.17.1.016008

Corradi, G. R., and Adamo, H. P. (2007). Intramolecular fluorescence resonance energy transfer between fused autofluorescent proteins reveals rearrangements of the $\mathrm{N}$ and C-terminal segments of the plasma membrane $\mathrm{Ca} 2+$ pump involved in the activation. J. Biol. Chem. 282, 35440-35448. doi: 10.1074/jbc.M703377200

Costa, R. M., Federov, N. B., Kogan, J. H., Murphy, G. G., Stern, J., Ohno, M., et al. (2002). Mechanism for the learning deficits in a mouse model of neurofibromatosis type 1. Nature 415, 526-530. doi: 10.1038 /nature711

Davis, S., Vanhoutte, P., Pages, C., Caboche, J., and Laroche, S. (2000). The MAPK/ERK cascade targets both Elk-1 and cAMP response element-binding protein to control long-term potentiation-dependent gene expression in the dentate gyrus in vivo. J. Neurosci. 20, 4563-4572.

De Koninck, P., and Schulman, H. (1998). Sensitivity of CaM kinase II to the frequency of $\mathrm{Ca}^{2+}$ oscillations. Science 279, 227-230. doi: 10.1126/science.279.5348.227

Duran, C., Thompson, C. H., Xiao, Q., and Hartzell, H. C. (2010). Chloride channels: often enigmatic, rarely predictable. Annu. Rev. Physiol. 72, 95-121. doi: 10.1146/annurevphysiol-021909-135811

Endoh, T., Funabashi, H., Mie, M., and Kobatake, E. (2005). Method for detection of specific nucleic acids by recombinant protein with fluorescent resonance energy transfer. Anal. Chem. 77, 4308-4314. doi: 10.1021/ac048491j

Fehr, M., Frommer, W. B., and Lalonde, S. (2002). Visualization of maltose uptake in living yeast cells by fluorescent nanosensors. Proc. Natl. Acad. Sci. U.S.A. 99, 9846-9851. doi: 10.1073/pnas.142089199

Fehr, M., Lalonde, S., Lager, I., Wolff, M. W., and Frommer, W. B. (2003). In vivo imaging of the dynamics of glucose uptake in the cytosol of COS-7 cells by fluorescent nanosensors. J. Biol. Chem. 278, 19127-19133. doi: 10.1074/jbc.M301333200

Förster, T. (1946). Energiewanderung und Fluoreszenz. Naturbreakwissenschaften 33, 166-175. doi: 10.1007/BF00585226

Fosbrink, M., Aye-Han, N. N., Cheong, R., Levchenko, A., and Zhang, J. (2010). Visualization of JNK activity dynamics with a genetically encoded fluorescent biosensor. Proc. Natl. Acad. Sci. U.S.A. 107, 5459-5464. doi: 10.1073/pnas.0909671107

Frost, N. A., Shroff, H., Kong, H., Betzig, E., and Blanpied, T. A. (2010). Single-molecule discrimination of discrete perisynaptic and distributed sites of actin filament assembly within dendritic spines. Neuron 67, 86-99. doi: 10.1016/j.neuron.2010.05.026

Fujii, H., Inoue, M., Okuno, H., Sano, Y., Takemoto-Kimura, S., Kitamura, K., et al. (2013). Nonlinear decoding and asymmetric representation of neuronal input information by CaMKII $\alpha$ and calcineurin. Cell Rep. 3, 978-987. doi: 10.1016/j.celrep.2013.03.033

Fujioka, A., Terai, K., Itoh, R. E., Aoki, K., Nakamura, T., Kuroda, S., et al. (2006). Dynamics of the Ras/ERK MAPK cascade as monitored by fluorescent probes. J. Biol. Chem. 281, 8917-8926. doi: 10.1074/jbc.M509344200
Fuller, B. G., Lampson, M. A., Foley, E. A., Rosasco-Nitcher, S., Le, K. V., Tobelmann, P., et al. (2008). Midzone activation of aurora B in anaphase produces an intracellular phosphorylation gradient. Nature 453, 1132-1136. doi: 10.1038 /nature 06923

Ganesan, S., Ameer-Beg, S. M., Ng, T. T., Vojnovic, B., and Wouters, F. S. (2006). A dark yellow fluorescent protein (YFP)-based resonance energy-accepting chromoprotein (REACh) for Förster resonance energy transfer with GFP. Proc. Natl. Acad. Sci. U.S.A. 103, 4089-4094. doi: 10.1073/pnas.0509922103

Gartner, U., Alpar, A., Behrbohm, J., Heumann, R., and Arendt, T. (2005). Enhanced Ras activity promotes spine formation in synRas mice neocortex. Neuroreport 16, 149-152. doi: 10.1097/00001756200502080-00016

Gavet, O., and Pines, J. (2010). Progressive activation of CyclinB1Cdk1 coordinates entry to mitosis. Dev. Cell 18, 533-543. doi: 10.1016/j.devcel.2010.02.013

Giovannini, M. G., Blitzer, R. D., Wong, T., Asoma, K., Tsokas, P., Morrison, J. H., et al. (2001). Mitogenactivated protein kinase regulates early phosphorylation and delayed expression of $\mathrm{Ca}^{2+} /$ calmodulindependent protein kinase II in long-term potentiation. J. Neurosci. 21, 7053-7062.

Goedhart, J., von Stetten, D., NoirclercSavoye, M., Lelimousin, M., Joosen, L., Hink, M. A., et al. (2012). Structure-guided evolution of cyan fluorescent proteins towards a quantum yield of 93\%. Nat. Commun. 3, 751. doi: 10.1038/ncomms 1738

Goldin, M., and Segal, M. (2003). Protein kinase $\mathrm{C}$ and ERK involvement in dendritic spine plasticity in cultured rodent hippocampal neurons. Eur. J. Neurosci. 17, 2529-2539. doi: 10.1046/j.1460-9568.2003.02694.x

Gonzalez, J. E., and Tsien, R. Y. (1995). Voltage sensing by fluorescence resonance energy transfer in single cells. Biophys. J. 69, 1272-1280. doi: 10.1016/S0006-3495(95)80029-9

Haj, F. G., Verveer, P. J., Squire, A., Neel, B. G., and Bastiaens, P. I. (2002). Imaging sites of receptor dephosphorylation by PTP1B on the surface of the endoplasmic reticulum. Science 295, 1708-1711. doi: 10.1126/science. 1067566

Han, J., Luby-Phelps, K., Das, B., Shu, X., Xia, Y., Mosteller, R. D., et al. (1998). Role of substrates 
and products of PI 3-kinase in regulating activation of Rac-related guanosine triphosphatases by Vav. Science 279, 558-560. doi: 10.1126/science.279.5350.558

Hao, Y., and Macara, I. G. (2008). Regulation of chromatin binding by a conformational switch in the tail of the Ran exchange factor RCC1. J. Cell Biol. 182, 827-836. doi: $10.1083 /$ jcb. 200803110

Hara, M., Bindokas, V., Lopez, J. P., Kaihara, K., Landa, L. R. Jr., Harbeck, M., et al. (2004). Imaging endoplasmic reticulum calcium with a fluorescent biosensor in transgenic mice. Am. J. Physiol. Cell Physiol. 287, C932-C938. doi: 10.1152/ajpcell.00151.2004

Harvey, C. D., Ehrhardt, A. G., Cellurale, C., Zhong, H., Yasuda, R., Davis, R. J., et al. (2008a). A genetically encoded fluorescent sensor of ERK activity. Proc. Natl. Acad. Sci. U.S.A. 105, 19264-19269. doi: 10.1073/pnas.0804598105

Harvey, C. D., Yasuda, R., Zhong, H., and Svoboda, K. (2008b). The spread of Ras activity triggered by activation of a single dendritic spine. Science 321, 136-140. doi: 10.1126/science. 1159675

Haspel, G., O'Donovan, M. J., and Hart, A. C. (2010). Motoneurons dedicated to either forward or backward locomotion in the nematode Caenorhabditis elegans. J. Neurosci. 30, 11151-11156. doi: 10.1523/JNEUROSCI.2244-10.2010

Hayashi, Y., and Majewska, A. K. (2005). Dendritic spine geometry: functional implication and regulation. Neuron 46, 529-532. doi: 10.1016/j.neuron. 2005.05.006

Heim, N., and Griesbeck, O. (2004). Genetically encoded indicators of cellular calcium dynamics based on troponin $\mathrm{C}$ and green fluorescent protein. J. Biol. Chem. 279, 14280-14286. doi: 10.1074/jbc.M312751200

Hitosugi, T., Sasaki, K., Sato, M., Suzuki, Y., and Umezawa, Y. (2007). Epidermal growth factor directs sex-specific steroid signaling through Src activation. J. Biol. Chem. 282, 10697-10706. doi: 10.1074/jbc.M610444200

Holtmaat, A., and Svoboda, K. (2009). Experience-dependent structural synaptic plasticity in the mammalian brain. Nat. Rev. Neurosci. 10, 647-658. doi: 10.1038/nrn2699

Homma, K., Niino, Y., Hotta, K., and Oka, K. (2008). $\mathrm{Ca}^{2+}$ influx through $\mathrm{P} 2 \mathrm{X}$ receptors induces actin cytoskeleton reorganization by the formation of cofilin rods in neurites.
Mol. Cell. Neurosci. 37, 261-270. doi: 10.1016/j.mcn.2007.10.001

Honda, A., Adams, S. R., Sawyer, C. L., Lev-Ram, V., Tsien, R. Y., and Dostmann, W. R. (2001). Spatiotemporal dynamics of guanosine 3', 5'-cyclic monophosphate revealed by a genetically encoded, fluorescent indicator. Proc. Natl. Acad. Sci. U.S.A. 98, 2437-2442. doi: 10.1073/pnas.051631298

Honkura, N., Matsuzaki, M., Noguchi, J., Ellis-Davies, G. C., and Kasai, H. (2008). The subspine organization of actin fibers regulates the structure and plasticity of dendritic spines. Neuron 57, 719-729. doi: 10.1016/j.neuron. 2008.01.013

Horikawa, K., Yamada, Y., Matsuda, T., Kobayashi, K., Hashimoto, M., Matsu-ura, T., et al. (2010). Spontaneous network activity visualized by ultrasensitive $\mathrm{Ca}(2+)$ indicators, yellow cameleon-nano. Nat. Methods 7, 729-732. doi: 10.1038/nmeth. 1488

Imamura, H., Nhat, K. P., Togawa, H., Saito, K., Iino, R., Kato-Yamada, Y., et al. (2009). Visualization of ATP levels inside single living cells with fluorescence resonance energy transfer-based genetically encoded indicators. Proc. Natl. Acad. Sci. U.S.A. 106, 15651-15656. doi: 10.1073/pnas.0904764106

Impey, S., Davare, M., Lesiak, A., Fortin, D., Ando, H., Varlamova, O., et al. (2010). An activity-induced microRNA controls dendritic spine formation by regulating Rac1-PAK signaling. Mol. Cell. Neurosci. 43, 146-156. doi: 10.1016/j.mcn.2009. 10.005

Impey, S., Obrietan, K., Wong, S. T., Poser, S., Yano, S., Wayman, G., et al. (1998a). Cross talk between ERK and PKA is required for $\mathrm{Ca}^{2+}$ stimulation of CREB-dependent transcription and ERK nuclear translocation. Neuron 21, 869-883. doi: 10.1016/S0896-6273(00)80602-9

Impey, S., Smith, D. M., Obrietan, K., Donahue, R., Wade, C., and Storm, D. R. (1998b). Stimulation of cAMP response element (CRE)mediated transcription during contextual learning. Nat. Neurosci. 1, 595-601.

Innocenti, M., Frittoli, E., Ponzanelli, I., Falck, J. R., Brachmann, S. M., Di Fiore, P. P., et al. (2003). Phosphoinositide 3-kinase activates Rac by entering in a complex with Eps8, Abil, and Sos-1. J. Cell Biol. 160, 17-23. doi: 10.1083/jcb.200206079

Irie, F., and Yamaguchi, Y. (2002). EphB receptors regulate dendritic spine development via intersectin, Cdc42 and N-WASP. Nat. Neurosci. 5, 1117-1118. doi: 10.1038/nn964

Jaworski, J., Spangler, S., Seeburg, D. P., Hoogenraad, C. C., and Sheng, M. (2005). Control of dendritic arborization by the phosphoinositide- $3^{\prime}$-kinaseAkt-mammalian target of rapamycin pathway. J. Neurosci. 25, 11300-11312. doi: 10.1523/ JNEUROSCI.2270-05.2005

Jin, L., Han, Z., Platisa, J., Wooltorton, J. R., Cohen, L. B., and Pieribone, V. A. (2012). Single action potentials and subthreshold electrical events imaged in neurons with a fluorescent protein voltage probe. Neuron 75, 779-785. doi: 10.1016/j.neuron.2012.06.040

Johnson, S. A., You, Z., and Hunter, T. (2007). Monitoring ATM kinase activity in living cells. DNA Repair (Amst.) 6, 1277-1284. doi: 10.1016/j.dnarep.2007.02.025

Joseph, J., Seervi, M., Sobhan, P. K., and Retnabai, S. T. (2011). High throughput ratio imaging to profile caspase activity: potential application in multiparameter high content apoptosis analysis and drug screening. PLoS ONE 6:e20114. doi: 10.1371/journal.pone.0020114

Kamioka, Y., Sumiyama, K., Mizuno, R., Sakai, Y., Hirata, E., Kiyokawa, E., et al. (2012). Live imaging of protein kinase activities in transgenic mice expressing FRET biosensors. Cell Struct. Funct. 37, 65-73. doi: 10.1247/csf.11045

Kawase, K., Nakamura, T., Takaya, A., Aoki, K., Namikawa, K., Kiyama, H., et al. (2006). GTP hydrolysis by the Rho family GTPase TC10 promotes exocytic vesicle fusion. Dev. Cell 11, 411-421. doi: 10.1016/j.devcel.2006.07.008

Kennedy, M. B., Bennett, M. K., and Erondu, N. E. (1983). Biochemical and immunochemical evidence that the "major postsynaptic density protein" is a subunit of a calmodulin-dependent protein kinase. Proc. Natl. Acad. Sci. U.S.A. 80, 7357-7361. doi: 10.1073/pnas.80.23.7357

Ketschek, A., and Gallo, G. (2010). Nerve growth factor induces axonal filopodia through localized microdomains of phosphoinositide 3-kinase activity that drive the formation of cytoskeletal precursors to filopodia. J. Neurosci. 30, 12185-12197. doi: 10.1523/JNEUROSCI.1740-10.2010

Kitano, M., Nakaya, M., Nakamura, T., Nagata, S., and Matsuda, M. (2008). Imaging of Rab5 activity identifies essential regulators for phagosome maturation. Nature 453, 241-245. doi: 10.1038/nature 06857

Kiyokawa, E., Aoki, K., Nakamura, T., and Matsuda, M. (2011) Spatiotemporal regulation of small GTPases as revealed by probes based on the principle of forster resonance energy transfer (FRET): implications for signaling and pharmacology. Annu. Rev. Pharmacol. Toxicol. 51, 337-358. doi: 10.1146/annurev-pharmtox010510-100234

Kolossov, V. L., Spring, B. Q., Clegg, R. M., Henry, J. J., Sokolowski, A., Kenis, P. J., et al. (2011). Development of a high-dynamic range, GFP-based FRET probe sensitive to oxidative microenvironments. Exp. Biol. Med. (Maywood) 236, 681-691. doi: 10.1258/ebm.2011.011009

Komatsu, N., Aoki, K., Yamada, M., Yukinaga, H., Fujita, Y., Kamioka, Y., et al. (2011). Development of an optimized backbone of FRET biosensors for kinases and GTPases. Mol. Biol. Cell 22, 4647-4656. doi: 10.1091/mbc.E11-01-0072

Kuner, T., and Augustine, G. J. (2000). A genetically encoded ratiometric indicator for chloride: capturing chloride transients in cultured hippocampal neurons. Neuron 27, 447-459. doi: 10.1016/S0896-6273(00)00056-8

Kunkel, M. T., Ni, Q., Tsien, R. Y., Zhang, J., and Newton, A. C. (2005). Spatio-temporal dynamics of protein kinase B/Akt signaling revealed by a genetically encoded fluorescent reporter. J. Biol. Chem. 280, 5581-5587. doi: 10.1074/jbc.M411534200

Kunkel, M. T., Toker, A., Tsien, R. Y., and Newton, A. C. (2007). Calciumdependent regulation of protein kinase $\mathrm{D}$ revealed by a genetically encoded kinase activity reporter. J. Biol. Chem. 282, 6733-6742. doi: 10.1074/jbc.M608086200

Kurokawa, K., Mochizuki, N., Ohba, Y., Mizuno, H., Miyawaki, A., and Matsuda, M. (2001). A pair of fluorescent resonance energy transfer-based probes for tyrosine phosphorylation of the CrkII adaptor protein in vivo. J. Biol. Chem. 276, 31305-31310. doi: 10.1074/jbc.M104341200

Kwok, S., Lee, C., Sanchez, S. A., Hazlett, T. L., Gratton, E., and Hayashi, Y. (2008). Genetically encoded probe for fluorescence lifetime imaging of CaMKII activity. Biochem. Biophys. Res. Commun. 369, 519-525. doi: 10.1016/j.bbrc.2008.02.070 
Lager, I., Fehr, M., Frommer, W. B., and Lalonde, S. (2003). Development of a fluorescent nanosensor for ribose. FEBS Lett. 553, 85-89. doi: 10.1016/S0014-5793(03)00976-1

Lam, A. J., St-Pierre, F., Gong, Y., Marshall, J. D., Cranfill, P. J., Baird, M. A., et al. (2012). Improving FRET dynamic range with bright green and red fluorescent proteins. Nat. Methods 9, 1005-1012. doi: 10.1038/nmeth.2171

Lantsman, K., and Tombes, R. M. (2005). CaMK-II oligomerization potential determined using CFP/YFP FRET. Biochim. Biophys. Acta 1746, 45-54. doi: 10.1016/j.bbamcr.2005.08.005

Lee, S. J., Escobedo-Lozoya, Y., Szatmari, E. M., and Yasuda, R. (2009). Activation of CaMKII in single dendritic spines during long-term potentiation. Nature 458, 299-304. doi: 10.1038/nature07842

Li, I. T., Chiang, J. J., and Truong, K. (2006). FRET evidence that an isoform of caspase-7 binds but does not cleave its substrate. Conf. Proc. IEEE Eng. Med. Biol. Soc. 1, 531-534. doi: 10.1109/IEMBS.2006.260832

Lin, C. W., Jao, C. Y., and Ting, A. Y. (2004). Genetically encoded fluorescent reporters of histone methylation in living cells. J. Am. Chem. Soc. 126, 5982-5983. doi: $10.1021 / \mathrm{ja} 038854 \mathrm{~h}$

Lisman, J., Schulman, H., and Cline, H. (2002). The molecular basis of CaMKII function in synaptic and behavioural memory. Nat. Rev. Neurosci. 3, 175-190. doi: 10.1038/nrn753

Lorenz, M., Yamaguchi, H., Wang, Y., Singer, R. H., and Condeelis, J. (2004). Imaging sites of $\mathrm{N}$ wasp activity in lamellipodia and invadopodia of carcinoma cells. Curr. Biol. 14, 697-703. doi: 10.1016/j.cub.2004.04.008

Macurek, L., Lindqvist, A., Lim, D., Lampson, M. A., Klompmaker, R., Freire, R., et al. (2008). Polo-like kinase-1 is activated by aurora A to promote checkpoint recovery. Nature 455, 119-123. doi: 10.1038/nature07185

Man, H. Y., Wang, Q., Lu, W. Y., Ju, W., Ahmadian, G., Liu, L., et al. (2003). Activation of PI3-kinase is required for AMPA receptor insertion during LTP of mEPSCs in cultured hippocampal neurons. Neuron 38, 611-624. doi: 10.1016/S0896-6273(03)00228-9

Matsu-ura, T., Michikawa, T., Inoue, T., Miyawaki, A., Yoshida, M., and Mikoshiba, K. (2006). Cytosolic inositol 1 4, 5-trisphosphate dynamics during intracellular calcium oscillations in living cells. J. Cell Biol. 173, 755-765. doi: 10.1083/jcb.200512141

Matsuzaki, M., Honkura, N., EllisDavies, G. C., and Kasai, H. (2004). Structural basis of long-term potentiation in single dendritic spines. Nature 429, 761-766. doi: 10.1038/nature 02617

Matus, A. (2005). Growth of dendritic spines: a continuing story. Curr. Opin. Neurobiol. 15, 67-72. doi: 10.1016/j.conb.2005.01.015

Meng, F., Suchyna, T. M., and Sachs, F. (2008). A fluorescence energy transfer-based mechanical stress sensor for specific proteins in situ. FEBS J. 275, 3072-3087. doi: 10.1111/j.1742-4658.2008.06461.x

Mitra, R. D., Silva, C. M., and Youvan, D. C. (1996). Fluorescence resonance energy transfer between blueemitting and red-shifted excitation derivatives of the green fluorescent protein. Gene 173, 13-17. doi: 10.1016/0378-1119(95)00768-7

Miyawaki, A. (2003). Visualization of the spatial and temporal dynamics of intracellular signaling. Dev . Cell 4, 295-305. doi: 10.1016/S15345807(03)00060-1

Miyawaki, A. (2005). Innovations in the imaging of brain functions using fluorescent proteins. Neuron 48, 189-199. doi: 10.1016/j.neuron.2005.10.003

Miyawaki, A., Llopis, J., Heim, R., McCaffery, J. M., Adams, J. A., Ikura, M., et al. (1997). Fluorescent indicators for $\mathrm{Ca}^{2+}$ based on green fluorescent proteins and calmodulin. Nature 388, 882-887. doi: $10.1038 / 42264$

Mizuno, H., Sassa, T., Higashijima, S. I., Okamoto, H., and Miyawaki, A. (2013). Transgenic zebrafish for ratiometric imaging of cytosolic and mitochondrial Ca response in teleost embryo. Cell Calcium 54, 236-245. doi: 10.1016/j.ceca.2013. 06.007

Mochizuki, N., Yamashita, S., Kurokawa, K., Ohba, Y., Nagai, T., Miyawaki, A., et al. (2001). Spatio-temporal images of growthfactor-induced activation of Ras and Rap1. Nature 411, 1065-1068. doi: 10.1038/35082594

Mower, A. F., Kwok, S., Yu, H., Majewska, A. K., Okamoto, K., Hayashi, Y., et al. (2011). Experience-dependent regulation of CaMKII activity within single visual cortex synapses in vivo. Proc. Natl. Acad. Sci. U.S.A. 108, 21241-21246. doi: 10.1073/pnas.1108261109

Murakoshi, H., Lee, S. J., and Yasuda, R. (2008). Highly sensitive and quantitative FRET-FLIM imaging in single dendritic spines using improved non-radiative YFP. Brain Cell Biol. 36, 31-42. doi: 10.1007/s11068-0089024-9

Murakoshi, H., Wang, H., and Yasuda, R. (2011). Local, persistent activation of Rho GTPases during plasticity of single dendritic spines. Nature 472, 100-104. doi: 10.1038/nature 09823

Murata, Y., Iwasaki, H., Sasaki, M., Inaba, K., and Okamura, Y. (2005). Phosphoinositide phosphatase activity coupled to an intrinsic voltage sensor. Nature 435, 1239-1243. doi: 10.1038/nature03650

Nagai, T., Sawano, A., Park, E. S., and Miyawaki, A. (2001). Circularly permuted green fluorescent proteins engineered to sense $\mathrm{Ca}^{2+}$. Proc. Natl. Acad. Sci. U.S.A. 98, 3197-3202. doi: 10.1073/pnas.051636098

Nagai, T., Yamada, S., Tominaga, T., Ichikawa, M., and Miyawaki, A. (2004). Expanded dynamic range of fluorescent indicators for $\mathrm{Ca}^{2+}$ by circularly permuted yellow fluorescent proteins. Proc. Natl. Acad. Sci. U.S.A. 101, 10554-10559. doi: 10.1073/pnas.0400417101

Nagai, Y., Miyazaki, M., Aoki, R., Zama, T., Inouye, S., Hirose, K., et al. (2000). A fluorescent indicator for visualizing cAMP-induced phosphorylation in vivo. Nat. Biotechnol. 18, 313-316. doi: 10.1038/73767

Nakai, J., Ohkura, M., and Imoto, K. (2001). A high signal-to-noise $\mathrm{Ca}^{2+}$ probe composed of a single green fluorescent protein. Nat. Biotechnol. 19, 137-141. doi: 10.1038/84397

Nakajima, T., Sato, M., Akaza, N., and Umezawa, Y. (2008). Cell-based fluorescent indicator to visualize brain-derived neurotrophic factor secreted from living neurons. ACS Chem. Biol. 3, 352-358. doi: $10.1021 / \mathrm{cb} 800052 \mathrm{v}$

Nakanishi, Y., Iida, S., UeokaNakanishi, H., Niimi, T., Tomioka, R., and Maeshima, M. (2013). Exploring dynamics of molybdate in living animal cells by a genetically encoded FRET nanosensor. PLoS ONE 8:e58175. doi: 10.1371/journal.pone.0058175

Nakayama, A. Y., Harms, M. B., and Luo, L. (2000). Small GTPases Rac and Rho in the maintenance of dendritic spines and branches in hippocampal pyramidal neurons. J. Neurosci. 20, 5329-5338.

Newman, R. H., Fosbrink, M. D., and Zhang, J. (2011). Genetically encodable fluorescent biosensors for tracking signaling dynamics in living cells. Chem. Rev. 111, 3614-3666. doi: 10.1021/cr100002u
Newman, R. H., and Zhang, J. (2008). Visualization of phosphatase activity in living cells with a FRETbased calcineurin activity sensor. Mol. Biosyst. 4, 496-501. doi: 10.1039/b720034j

Nguyen, A. W., and Daugherty, P. S. (2005). Evolutionary optimization of fluorescent proteins for intracellular FRET. Nat. Biotechnol. 23, 355-360. doi: 10.1038/nbt1066

Ni, Q., and Zhang, J. (2010). Dynamic visualization of cellular signaling. Adv. Biochem. Eng. Biotechnol. 119, 79-97. doi: 10.1007/10_2008_48

Ni, Z., Mark, M. E., Cai, X., and Mao, Q. (2010). Fluorescence resonance energy transfer (FRET) analysis demonstrates dimer/oligomer formation of the human breast cancer resistance protein (BCRP/ABCG2) in intact cells. Int. J. Biochem. Mol. Biol. 1, 1-11.

Nikolaev, V. O., Bunemann, M., Hein, L., Hannawacker, A., and Lohse, M. J. (2004). Novel single chain cAMP sensors for receptorinduced signal propagation. J. Biol. Chem. 279, 37215-37218. doi: 10.1074/jbc.C400302200

Nikolaev, V. O., Gambaryan, S., and Lohse, M. J. (2006). Fluorescent sensors for rapid monitoring of intracellular cGMP. Nat. Methods 3, 23-25. doi: 10.1038/nmeth816

Nishi, M., Tanaka, M., Matsuda, K., Sunaguchi, M., and Kawata, M. (2004). Visualization of glucocorticoid receptor and mineralocorticoid receptor interactions in living cells with GFP-based fluorescence resonance energy transfer. J. Neurosci. 24, 4918-4927. doi: 10.1523/JNEUROSCI.5495-03.2004

Nishioka, T., Aoki, K., Hikake, K., Yoshizaki, H., Kiyokawa, E., and Matsuda, M. (2008). Rapid turnover rate of phosphoinositides at the front of migrating MDCK cells. Mol. Biol. Cell 19, 4213-4223. doi: 10.1091/mbc.E0803-0315

Nishioka, T., Frohman, M. A., Matsuda, M., and Kiyokawa, E. (2010). Heterogeneity of phosphatidic acid levels and distribution at the plasma membrane in living cells as visualized by a Foster resonance energy transfer (FRET) biosensor. J. Biol. Chem. 285, 35979-35987. doi: 10.1074/jbc.M110.153007

Ohashi, T., Galiacy, S. D., Briscoe, G., and Erickson, H. P. (2007). An experimental study of GFPbased FRET, with application to intrinsically unstructured proteins. Protein Sci. 16, 1429-1438. doi: 10.1110/ps.072845607 
Ohkura, M., Sasaki, T., Sadakari, J., Gengyo-Ando, K., KagawaNagamura, Y., Kobayashi, C., et al. (2012). Genetically encoded green fluorescent $\mathrm{Ca}^{2+}$ indicators with improved detectability for neuronal $\mathrm{Ca}^{2+}$ signals. PLoS ONE 7:e51286. doi: 10.1371/journal.pone.0051286

Oikawa, T., Yamaguchi, H., Itoh, T., Kato, M., Ijuin, T., Yamazaki, D., et al. (2004). PtdIns(3 4, 5)P3 binding is necessary for WAVE2induced formation of lamellipodia. Nat. Cell Biol. 6, 420-426. doi: 10.1038/ncbl125

Okamoto, K., Bosch, M., and Hayashi, Y. (2009). The roles of CaMKII and F-actin in the structural plasticity of dendritic spines: a potential molecular identity of a synaptic tag? Physiology (Bethesda) 24, 357-366. doi: 10.1152/physiol.00029.2009

Okamoto, K., and Hayashi, Y. (2006). Visualization of F-actin and G-actin equilibrium using fluorescence resonance energy transfer (FRET) in cultured cells and neurons in slices. Nat. Protoc. 1, 911-919. doi: 10.1038/nprot.2006.122

Okamoto, K., Nagai, T., Miyawaki, A., and Hayashi, Y. (2004). Rapid and persistent modulation of actin dynamics regulates postsynaptic reorganization underlying bidirectional plasticity. Nat. Neurosci. 7 , 1104-1112. doi: 10.1038/nn1311

Okamoto, K., Narayanan, R., Lee, S. H., Murata, K., and Hayashi, Y. (2007). The role of CaMKII as an F-actin-bundling protein crucial for maintenance of dendritic spine structure. Proc. Natl. Acad. Sci. U.S.A. 104, 6418-6423. doi: 10.1073/pnas.0701656104

Okumoto, S., Looger, L. L., Micheva, K. D., Reimer, R. J., Smith, S. J., and Frommer, W. B. (2005). Detection of glutamate release from neurons by genetically encoded surface-displayed FRET nanosensors. Proc. Natl. Acad. Sci. U.S.A. 102, 8740-8745. doi: 10.1073/pnas.0503274102

Onuki, R., Nagasaki, A., Kawasaki, H., Baba, T., Uyeda, T. Q., and Taira, K. (2002). Confirmation by FRET in individual living cells of the absence of significant amyloid beta -mediated caspase 8 activation. Proc. Natl. Acad. Sci. U.S.A. 99, 14716-14721. doi: 10.1073/pnas.232177599

Ouyang, M., Lu, S., Li, X. Y., Xu, J., Seong, J., Giepmans, B. N., et al. (2008). Visualization of polarized membrane type 1 matrix metalloproteinase activity in live cells by fluorescence resonance energy transfer imaging. J. Biol.
Chem. 283, 17740-17748. doi: 10.1074/jbc.M709872200

Papusheva, E., Mello de Queiroz, F., Dalous, J., Han, Y., Esposito, A., Jares-Erijmanxa, E. A., et al. (2009). Dynamic conformational changes in the FERM domain of FAK are involved in focal-adhesion behavior during cell spreading and motility. J. Cell. Sci. 122, 656-666. doi: $10.1242 /$ jcs. 028738

Parrini, M. C., Camonis, J., Matsuda, M., and de Gunzburg, J. (2009). Dissecting activation of the PAK1 kinase at protrusions in living cells. J. Biol. Chem. 284, 24133-24143. doi: 10.1074/jbc.M109.015271

Patterson, S. L., Pittenger, C., Morozov, A., Martin, K. C., Scanlin, H., Drake, C., et al. (2001). Some forms of cAMP-mediated longlasting potentiation are associated with release of BDNF and nuclear translocation of phospho-MAP kinase. Neuron 32, 123-140. doi: 10.1016/S0896-6273(01)00443-3

Piljic, A., de Diego, I., Wilmanns, M., and Schultz, C. (2011). Rapid development of genetically encoded FRET reporters. ACS Chem. Biol. 6, 685-691. doi: 10.1021/cb100402n

Randriamampita, C., Mouchacca, P., Malissen, B., Marguet, D., Trautmann, A., and Lellouch, A. C. (2008). A novel ZAP-70 dependent FRET based biosensor reveals kinase activity at both the immunological synapse and the antisynapse. PLoS ONE 3:e1521. doi: 10.1371/journal.pone.0001521

Rizzo, M. A., Springer, G., Segawa, K., Zipfel, W. R., and Piston, D. W. (2006). Optimization of pairings and detection conditions for measurement of FRET between cyan and yellow fluorescent proteins. Microsc. Microanal. 12, 238-254. doi: 10.1017/S1431927606060235

Rizzo, M. A., Springer, G. H., Granada, B., and Piston, D. W. (2004). An improved cyan fluorescent protein variant useful for FRET. Nat. Biotechnol. 22, 445-449. doi: 10.1038/nbt 945

Roberson, E. D., English, J. D., Adams, J. P., Selcher, J. C., Kondratick, C., and Sweatt, J. D. (1999). The mitogen-activated protein kinase cascade couples PKA and PKC to cAMP response element binding protein phosphorylation in area CAl of hippocampus. J. Neurosci. 19, 4337-4348.

Sakai, R., Repunte-Canonigo, V., Raj, C. D., and Knöpfel, T. (2001). Design and characterization of a DNA-encoded, voltagesensitive fluorescent protein. Eur.
J. Neurosci. 13, 2314-2318. doi: 10.1046/j.0953-816x.2001.01617.x

Sanes, J. R., and Lichtman, J. W. (1999). Can molecules explain longterm potentiation? Nat. Neurosci. 2, 597-604. doi: 10.1038/10154

Saneyoshi, T., and Hayashi, Y. (2012). The $\mathrm{Ca}^{2+}$ and Rho GTPase signaling pathways underlying activity-dependent actin remodeling at dendritic spines. Cytoskeleton (Hoboken) 69, 545-554. doi: $10.1002 / \mathrm{cm} .21037$

Sasaki, K., Ito, T., Nishino, N., Khochbin, S., and Yoshida, M. (2009). Real-time imaging of histone $\mathrm{H} 4$ hyperacetylation in living cells. Proc. Natl. Acad. Sci. U.S.A. 106, 16257-16262. doi: 10.1073/pnas.0902150106

Sasaki, K., Sato, M., and Umezawa, Y. (2003). Fluorescent indicators for Akt/protein kinase B and dynamics of Akt activity visualized in living cells. J. Biol. Chem. 278, 30945-30951. doi: 10.1074/jbc.M212167200

Sato, M., Hida, N., Ozawa, T., and Umezawa, Y. (2000). Fluorescent indicators for cyclic GMP based on cyclic GMP-dependent protein kinase Ialpha and green fluorescent proteins. Anal. Chem. 72, 5918-5924. doi: 10.1021/ac0006167

Sato, M., Kawai, Y., and Umezawa, Y. (2007). Genetically encoded fluorescent indicators to visualize protein phosphorylation by extracellular signal-regulated kinase in single living cells. Anal. Chem. 79, 2570-2575. doi: 10.1021/ac062171d

Sato, M., Ozawa, T., Inukai, K., Asano, T., and Umezawa, Y. (2002). Fluorescent indicators for imaging protein phosphorylation in single living cells. Nat. Biotechnol. 20, 287-294. doi: 10.1038/nbt0302-287

Sato, M., Ueda, Y., Shibuya, M., and Umezawa, Y. (2005a). Locating inositol 14,5-trisphosphate in the nucleus and neuronal dendrites with genetically encoded fluorescent indicators. Anal. Chem. 77, 4751-4758. doi: 10.1021/ac040195j

Sato, M., Hida, N., and Umezawa, Y. (2005b). Imaging the nanomolar range of nitric oxide with an amplifier-coupled fluorescent indicator in living cells. Proc. Natl. Acad. Sci. U.S.A. 102, 14515-14520. doi: 10.1073/pnas.0505136102

Sato, M., Ueda, Y., Takagi, T., and Umezawa, Y. (2003). Production of PtdInsP3 at endomembranes is triggered by receptor endocytosis. Nat. Cell Biol. 5, 1016-1022. doi: 10.1038/ncb1054

Sato, M., Ueda, Y., and Umezawa, Y. (2006a). Imaging diacylglycerol dynamics at organelle membranes. Nat. Methods 3, 797-799. doi: 10.1038/nmeth930

Sato, M., Nakajima, T., Goto, M., and Umezawa, Y. (2006b). Cellbased indicator to visualize picomolar dynamics of nitric oxide release from living cells. Anal. Chem. 78, 8175-8182. doi: 10.1021/ac061791b

Shaner, N. C., Steinbach, P. A., and Tsien, R. Y. (2005). A guide to choosing fluorescent proteins. Nat. Methods 2, 905-909. doi: $10.1038 /$ nmeth 819

Shimozono, S., Iimura, T., Kitaguchi, T., Higashijima, S., and Miyawaki, A. (2013). Visualization of an endogenous retinoic acid gradient across embryonic development. Nature 496, 363-366. doi: 10.1038/nature12037

Shinohara, M., Terada, Y., Iwamatsu, A., Shinohara, A., Mochizuki, N., Higuchi, M., et al. (2002). SWAP70 is a guanine-nucleotide-exchange factor that mediates signalling of membrane ruffling. Nature 416, 759-763. doi: 10.1038/416759a

Spacek, J., and Harris, K. M. (2004). Trans-endocytosis via spinules in adult rat hippocampus. J. Neurosci. 24, 4233-4241. doi: 10.1523/JNEUROSCI.0287-04.2004

Star, E. N., Kwiatkowski, D. J., and Murthy, V. N. (2002). Rapid turnover of actin in dendritic spines and its regulation by activity. Nat. Neurosci. 5, 239-246. doi: $10.1038 / \mathrm{nn} 811$

Stryer, L. (1978). Fluorescence energy transfer as a spectroscopic ruler. Annu. Rev. Biochem. 47, 819-846. doi: 10.1146/annurev.bi.47.070178. 004131

Suzuki, Y., Yasunaga, T., Ohkura, R., Wakabayashi, T., and Sutoh, K. (1998). Swing of the lever arm of a myosin motor at the isomerization and phosphate-release steps. Nature 396, 380-383. doi: 10.1038/ 24640

Takao, K., Okamoto, K., Nakagawa, T., Neve, R. L., Nagai, T., Miyawaki, A., et al. (2005). Visualization of synaptic $\mathrm{Ca}^{2+} /$ calmodulindependent protein kinase II activity in living neurons. J. Neurosci. 25, 3107-3112. doi: 10.1523/JNEUROSCI.0085-05.2005

Takaya, A., Ohba, Y., Kurokawa, K., and Matsuda, M. (2004). RalA activation at nascent lamellipodia of epidermal growth factor-stimulated Cos7 cells and migrating MadinDarby canine kidney cells. Mol. Biol. Cell 15, 2549-2557. doi: 10.1091/mbc.E03-11-0857

Tanimura, A., Nezu, A., Morita, T., Turner, R. J., and Tojyo, Y. (2004). 
Fluorescent biosensor for quantitative real-time measurements of inositol 14 , 5-trisphosphate in single living cells. J. Biol. Chem. 279, 38095-38098. doi: 10.1074/jbc.C400312200

Tashiro, A., Minden, A., and Yuste, R. (2000). Regulation of dendritic spine morphology by the rho family of small GTPases: antagonistic roles of Rac and Rho. Cereb. Cortex 10, 927-938. doi: $10.1093 /$ cercor/10.10.927

Terai, K., and Matsuda, M. (2005). Ras binding opens c-Raf to expose the docking site for mitogenactivated protein kinase kinase. EMBO Rep. 6, 251-255. doi: 10.1038/sj.embor.7400349

Terai, K., and Matsuda, M. (2006). The amino-terminal B-Raf-specific region mediates calcium-dependent homo- and hetero-dimerization of Raf. EMBO J. 25, 3556-3564. doi: 10.1038/sj.emboj.7601241

Thomas, C. C., Dowler, S., Deak, M., Alessi, D. R., and van Aalten, D. M. (2001). Crystal structure of the phosphatidylinositol 3, 4-bisphosphate-binding pleckstrin homology $(\mathrm{PH})$ domain of tandem $\mathrm{PH}$-domain-containing protein 1 (TAPP1): molecular basis of lipid specificity. Biochem. J. 358, 287-294. doi: 10.1042/0264-6021:3580287

Thunemann, M., Wen, L., Hillenbrand, M., Vachaviolos, A., Feil, S., Ott, T., et al. (2013). Transgenic Mice for cGMP Imaging. Circ. Res. 113, 365-371. doi: 10.1161/CIRCRESAHA.113.301063

Ting, A. Y., Kain, K. H., Klemke, R. L., and Tsien, R. Y. (2001). Genetically encoded fluorescent reporters of protein tyrosine kinase activities in living cells. Proc. Natl. Acad. Sci. U.S.A. 98, 15003-15008. doi: $10.1073 /$ pnas. 211564598

Tomida, T., Takekawa, M., O'Grady, P., and Saito, H. (2009). Stimulusspecific distinctions in spatial and temporal dynamics of stressactivated protein kinase kinase kinases revealed by a fluorescence resonance energy transfer biosensor. Mol. Cell. Biol. 29, 6117-6127. doi: 10.1128/MCB.00571-09

Tsutsui, H., Karasawa, S., Okamura, Y., and Miyawaki, A. (2008). Improving membrane voltage measurements using FRET with new fluorescent proteins. Nat. Methods 5, 683-685. doi: 10.1038/nmeth.1235

Tunceroglu, A., Matsuda, M., and Birge, R. B. (2010). Real-time fluorescent resonance energy transfer analysis to monitor drug resistance in chronic myelogenous leukemia.
Mol. Cancer Ther. 9, 3065-3073. doi: 10.1158/1535-7163.MCT-10-0623

Ueda, Y., and Hayashi, Y. (2013). $\mathrm{PIP}_{3}$ regulates spinule formation in dendritic spines during structural long-term potentiation. J. Neurosci. 33, 11040-11047. doi: 10.1523/JNEUROSCI.3122-12.2013

Uemura, K., Lill, C. M., Li, X., Peters, J. A., Ivanov, A., Fan, Z., et al. (2009). Allosteric modulation of PSl/gammasecretase conformation correlates with amyloid beta(42/40) ratio. PLoS ONE 4:e7893. doi: 10.1371/journal.pone.0007893

Vanderklish, P. W., Krushel, L. A., Holst, B. H., Gally, J. A., Crossin, K. L., and Edelman, G. M. (2000). Marking synaptic activity in dendritic spines with a calpain substrate exhibiting fluorescence resonance energy transfer. Proc. Natl. Acad. Sci. U.S.A. 97, 2253-2258. doi: 10.1073/pnas.040565597

van Diepen, M. T., Parsons, M., Downes, C. P., Leslie, N. R., Hindges, R., and Eickholt, B. J. (2009). MyosinV controls PTEN function and neuronal cell size. Nat. Cell Biol. 11, 1191-1196. doi: 10.1038/ncb1961

Vazquez, L. E., Chen, H. J., Sokolova, I., Knuesel, I., and Kennedy, M. B. (2004). SynGAP regulates spine formation. J. Neurosci. 24, 8862-8872. doi: 10.1523/JNEUROSCI.3213-04.2004

Vilardaga, J. P., Bunemann, M., Krasel, C., Castro, M., and Lohse, M. J. (2003). Measurement of the millisecond activation switch of $G$ protein-coupled receptors in living cells. Nat. Biotechnol. 21, 807-812. doi: $10.1038 /$ nbt 838

Vinkenborg, J. L., Nicolson, T. J., Bellomo, E. A., Koay, M. S., Rutter, G. A., and Merkx, M. (2009). Genetically encoded FRET sensors to monitor intracellular $\mathrm{Zn}^{2+}$ homeostasis. Nat. Methods 6, 737-740. doi: 10.1038/nmeth.1368

Violin, J. D., Zhang, J., Tsien, R. Y., and Newton, A. C. (2003). A genetically encoded fluorescent reporter reveals oscillatory phosphorylation by protein kinase C. J. Cell Biol. 161, 899-909. doi: 10.1083/jcb.200302125

Wallace, D. J., Meyer zum Alten Borgloh, S., Astori, S., Yang, Y., Bausen, M., Kugler, S., et al. (2008). Single-spike detection in vitro and in vivo with a genetic $\mathrm{Ca} 2+$ sensor. Nat. Methods 5, 797-804. doi: 10.1038/nmeth. 1242

Waltereit, R., Dammermann, B., Wulff, P., Scafidi, J., Staubli, U., Kauselmann, G., et al.
(2001). Arg3.1/Arc mRNA induction by $\mathrm{Ca}^{2+}$ and cAMP requires protein kinase $\mathrm{A}$ and mitogen-activated protein kinase/extracellular regulated kinase activation. J. Neurosci. 21, 5484-5493.

Wang, D., McMahon, S., Zhang, Z., and Jackson, M. B. (2012). Hybrid voltage sensor imaging of electrical activity from neurons in hippocampal slices from transgenic mice. J. Neurophysiol. 108, 3147-3160. doi: 10.1152/jn.00722.2012

Wang, Y., Botvinick, E. L., Zhao, Y., Berns, M. W., Usami, S., Tsien, R. Y., et al. (2005). Visualizing the mechanical activation of Src. Nature 434, 1040-1045. doi: 10.1038/nature03469

Ward, M. E., Wu, J. Y., and Rao, Y. (2004). Visualization of spatially and temporally regulated $\mathrm{N}$ WASP activity during cytoskeletal reorganization in living cells. Proc. Natl. Acad. Sci. U.S.A. 101, 970-974. doi: 10.1073/pnas.03062 58101

Wu, G. Y., Deisseroth, K., and Tsien, R. W. (2001). Spaced stimuli stabilize MAPK pathway activation and its effects on dendritic morphology. Nat. Neurosci. 4, 151-158. doi: 10.1038/83976

Xu, X., Gerard, A. L., Huang, B. C., Anderson, D. C., Payan, D. G., and Luo, Y. (1998). Detection of programmed cell death using fluorescence energy transfer. Nucleic Acids Res. 26, 2034-2035. doi: 10.1093/nar/26.8.2034

Yamada, Y., Michikawa, T., Hashimoto, M., Horikawa, K., Nagai, T., Miyawaki, A., et al. (2011). Quantitative comparison of genetically encoded $\mathrm{Ca}$ indicators in cortical pyramidal cells and cerebellar Purkinje cells. Front. Cell. Neurosci. 5:18. doi: 10.3389/fncel.2011.00018

Yamaguchi, Y., Shinotsuka, N., Nonomura, K., Takemoto, K., Kuida, K., Yosida, H., et al. (2011). Live imaging of apoptosis in a novel transgenic mouse highlights its role in neural tube closure. J. Cell Biol. 195, 1047-1060. doi: 10.1083/jcb.201104057

Yang, J., Zhang, Z., Lin, J., Lu, J., Liu, B. F., Zeng, S., et al. (2007). Detection of MMP activity in living cells by a genetically encoded surface-displayed FRET sensor. Biochim. Biophys. Acta 1773, 400-407. doi: 10.1016/j.bbamcr. 2006.11.002

Yano, T., Oku, M., Akeyama, N., Itoyama, A., Yurimoto, H., Kuge, S., et al. (2010). A novel fluorescent sensor protein for visualization of redox states in the cytoplasm and in peroxisomes. Mol. Cell. Biol. 30 3758-3766. doi: 10.1128/MCB.00121-10

Yasuda, R. (2006). Imaging spatiotemporal dynamics of neuronal signaling using fluorescence resonance energy transfer and fluorescence lifetime imaging microscopy. Curr. Opin. Neurobiol. 16, 551-561. doi: 10.1016/j.conb.2006. 08.012

Yasuda, R. (2012). Studying signal transduction in single dendritic spines. Cold Spring Harb. Perspect. Biol. 4, 005611. doi: 10.1101/cshperspect.a005611

Yasuda, R., Harvey, C. D., Zhong, H., Sobczyk, A., van Aelst, L., and Svoboda, K. (2006). Supersensitive Ras activation in dendrites and spines revealed by two-photon fluorescence lifetime imaging. Nat. Neurosci. 9, 283-291. doi: 10.1038/nn1635

Yoshizaki, H., Ohba, Y., Kurokawa, K., Itoh, R. E., Nakamura, T., Mochizuki, N., et al. (2003). Activity of Rho-family GTPases during cell division as visualized with FRET-based probes. J. Cell Biol. 162, 223-232. doi: 10.1083/jcb.200212049

Zaccolo, M., and Pozzan, T. (2002). Discrete microdomains with high concentration of cAMP in stimulated rat neonatal cardiac myocytes. Science 295, 1711-1715. doi: 10.1126/science.1069982

Zacharias, D. A., Violin, J. D., Newton, A. C., and Tsien, R. Y. (2002) Partitioning of lipid-modified monomeric GFPs into membrane microdomains of live cells. Science 296, 913-916. doi: 10.1126/science.1068539

Zeng, W., Seward, H. E., MalnasiCsizmadia, A., Wakelin, S., Woolley, R. J., Cheema, G. S., et al. (2006). Resonance energy transfer between green fluorescent protein variants: complexities revealed with myosin fusion proteins. Biochemistry 45, 10482-10491. doi: 10.1021/bi060943u

Zhang, H., and Macara, I. G. (2006) The polarity protein PAR-3 and TIAM1 cooperate in dendritic spine morphogenesis. Nat. Cell Biol. 8, 227-237. doi: 10.1038/ncb1368

Zhang, J., Campbell, R. E., Ting, A. Y., and Tsien, R. Y. (2002). Creating new fluorescent probes for cell biology. Nat. Rev. Mol. Cell Biol. 3, 906-918. doi: 10.1038/nrm976

Zhang, J., Chen, L., Raina, H., Blaustein, M. P., and Wier, W. 
G. (2010). In vivo assessment of artery smooth muscle $[\mathrm{Ca} 2+] \mathrm{i}$ and MLCK activation in FRET-based biosensor mice. Am. J. Physiol. Heart Circ. Physiol. 299, H946-H956. doi: 10.1152/ajpheart.00359.2010

Zhang, J., Ma, Y., Taylor, S. S., and Tsien, R. Y. (2001). Genetically encoded reporters of protein kinase A activity reveal impact of substrate tethering. Proc. Natl. Acad. Sci. U.S.A. 98, 14997-15002. doi: 10.1073/pnas. 211566798

Zhao, Y., Araki, S., Wu, J., Teramoto, T., Chang, Y. F., Nakano, M., et al.
(2011). An expanded palette of genetically encoded $\mathrm{Ca}^{2+}$ indicators. Science 333, 1888-1891. doi: 10.1126/science.1208592

Zhu, J. J., Qin, Y., Zhao, M., Van Aelst, L., and Malinow, R. (2002). Ras and Rap control AMPA receptor trafficking during synaptic plasticity. Cell 110, 443-455. doi: 10.1016/S0092-8674(02)00897-8

Conflict of Interest Statement: Yasunori Hayashi is partly supported by Takeda Pharmaceuticals Co. Ltd. and Fujitsu Laboratories. The other authors declare that the research was conducted in the absence of any commercial or financial relationships that could be construed as a potential conflict of interest.

Received: 30 July 2013; accepted: 23 September 2013; published online: 10 October 2013.

Citation: Ueda Y, Kwok S and Hayashi $Y$ (2013) Application of FRET probes in the analysis of neuronal plasticity. Front. Neural Circuits 7:163. doi: 10.3389/fncir. 2013.00163
This article was submitted to the journal Frontiers in Neural Circuits.

Copyright (c) 2013 Ueda, Kwok and Hayashi. This is an open-access article distributed under the terms of the Creative Commons Attribution License (CC BY). The use, distribution or reproduction in other forums is permitted, provided the original author(s) or licensor are credited and that the original publication in this journal is cited, in accordance with accepted academic practice. No use, distribution or reproduction is permitted which does not comply with these terms. 